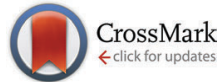

Cite this: Phys. Chem. Chem. Phys., 2015, 17, 13743

Received 16th February 2015, Accepted 20th April 2015

DOI: $10.1039 / \mathrm{c} 5 \mathrm{cp} 01000 \mathrm{~d}$

www.rsc.org/pccp

\title{
Alcohol-soluble bis(tpy)thiophenes: new building units for constitutional dynamic conjugated polyelectrolytes $\dagger$
}

\author{
Pavla Štenclová-Bláhová, Jan Svoboda, * Ivana Šloufová and Jiři Vohlídal*
}

\begin{abstract}
New building units (unimers) for metallo-supramolecular polymers 2,5-bis $\left(2,2^{\prime}: 6^{\prime}, 2^{\prime \prime}\right.$-terpyridine-4' -yl)thiophene, $\mathbf{M}$, and $5,5^{\prime}$-bis $\left(2,2^{\prime}: 6^{\prime}, 2^{\prime \prime}\right.$-terpyridine- $\left.4^{\prime}-\mathrm{yl}\right)\left(2,2^{\prime}\right.$-bithiophene), B, with ionic groups attached to thiophene rings are prepared by the modification of corresponding bromo-precursors and assembled with $\mathrm{Zn}^{2+}$ and $\mathrm{Fe}^{2+}$ ions into alcohol-soluble conjugated constitutional-dynamic polyelectrolytes (polyelectrolyte dynamers). Ionization of side groups only slightly affects the absorption spectra of unimers as well as dynamers but dramatically changes their solubility. Cyclic conformations of unimer molecules resulting from intramolecular interactions between tpy end-groups and cationic or polar $\left(-\mathrm{CH}_{2} \mathrm{Br}\right)$ side groups are proposed to explain the spectral conformity of the $\mathbf{M}$ - and $\mathbf{B}$-type unimers and their dynamers and also inhibition of the ionization reaction with tpy end-groups. The absorption spectra and excitation profiles of Raman spectra show that mainly the red arm of the metal-to-ligand charge transfer band of Fe-dynamers is significantly contributed with transitions involving thiophene rings. The constitutional dynamics of Zn-dynamers is fast while that of Fe-dynamers is so slow that it allows effective separation of the dynamer to fractions in SEC columns. Electronic spectra and viscosity measurements proved that excess of $\mathrm{Fe}^{2+}$ ions results in shortening of the dynamer chains and their end-capping by these ions.
\end{abstract}

\section{Introduction}

Metallo-supramolecular polymers (MSP) are an important subclass of dynamers. ${ }^{1,2}$ A molecule of a linear MSP is composed of low-molar-mass or oligomeric units with two chelating endgroups (metal-ion receptors) that enable metal-ion induced reversible self-assembly of the units into chains. Metal ions that facilitate this self-assembly are usually referred to as ion couplers. Depending on the strength of interactions between the end-groups and ion couplers and solubility, molecules of MSPs exhibit constitutional dynamics either at increased temperature, or in solution, or both. The constitutional dynamics gives to MSPs (i) processing advantages, (ii) responsiveness to external stimuli (adaptability), (iii) possibility of tuning the properties or healing structure defects by post-synthesis exchanges of oligomer molecules and/or ion-couplers. The dynamics of MSPs is controlled by the rates of opposite reactions underlying coordination equilibriums, i.e., by the rate of chemical relaxation.

Charles University in Prague, Faculty of Science, Department of Physical and Macromolecular Chemistry, Hlavova 2030, CZ-128 40, Prague 2, Czech Republic. E-mail: jan.svoboda@natur.cuni.cz, jiri.vohlidal@natur.cuni.cz;

Fax: +420 224919752; Tel: +420 221951310

$\dagger$ Electronic supplementary information (ESI) available. See DOI: 10.1039/ c5cp01000d
As the field of dynamers is relatively new, the related terminology has not yet been established, which brings about ambiguity of the term oligomer. Under the dynamics promoting conditions, dynamer molecules are typically composed of only less number of assembled units, most often oligomeric molecules. Such a dynamer is a "superior oligomer" of hierarchically lower oligomer(s). Ambiguity of the term oligomer is thus obvious. Therefore, we use throughout this paper the term unimer for an oligomer utilized as a "monomer" in the preparation of a dynamer, as proposed by Ciferri et $a l^{3}$

The MSPs composed of conjugated unimers are of interest as potential materials for devices with applications based on the light/electricity inter-conversion and non-linear optical phenomena (light-emitting devices, photovoltaic cells, etc.). ${ }^{4-22}$ High attention has been paid to MSPs derived from conjugated oligomers with tridentate $2,2^{\prime}: 6^{\prime}, 2^{\prime \prime}$-terpyridine- $4^{\prime}$-yl (tpy) end units that prefer facial and meridian coordination to metal ions such as $\mathrm{Ru}^{2+}, \mathrm{Fe}^{2+}, \mathrm{Zn}^{2+}$ and $\mathrm{Co}^{2+}$, thus giving well defined linear chains. ${ }^{20,23-25}$ However, conjugated MSPs as well as their unimers suffer from poor solubility in solvents suitable for their solution processing. MSPs constituted of bis(tpy)oligoarylenes are poorly soluble or insoluble in overwhelming majority of solvents. They are not very easily soluble in solvents such as dimethylsulfoxide (DMSO), acetonitrile (AN), and dimethylformamide (DMF), which are not very favorable for preparing good MSP layers. 
Poor solubility of conjugated linear MSPs originates from rather high stiffness of their chains that strongly supports the inter-chain interactions and suppresses the intra-chain ones. The stiffness of conjugated MSP chains is a logical consequence of their chemical constitution. It mainly stems from two effects: (i) increased rigidity of conjugated chains of inbuilt unimers, and (ii) ionene structure causing extension of MSP chains due to the electrostatic repulsion between main-chain cations.

An increase in the solubility of conjugated MSPs in mediumpolar solvents achieved by introducing pendant alkyl groups to unimeric units $^{24}$ is insufficient. Future technologies require materials soluble in "green solvents" such as alcohols and aqueous solutions and in solvents providing good polymer films. Such solubility of conjugated MSPs can be potentially achieved by introducing pendant ionic groups into unimers. In the present paper, we report on the preparation and basic properties of the ionic unimers of the bis(tpy)thiophene type and their transformation into conjugated MSPs by means of coordination to $\mathrm{Zn}^{2+}$ and $\mathrm{Fe}^{2+}$ ion couplers. These compounds might be classified as conjugated polyelectrolyte dynamers though, according to the molecular structure they are hybrids of polyelectrolytes and ionenes since their chains contain pendent ionic groups as well as charged main chain atoms. ${ }^{26,27}$

\section{Results and discussion}

The unimers prepared and studied as well as their abbreviations are shown in Chart 1. Metallo-supramolecular dynamers prepared from these unimers are denoted with the prefix $\mathbf{P}_{\mathbf{Z n}}$ (dynamers with $\mathrm{Zn}^{2+}$ ion couplers) or $\mathbf{P}_{\mathrm{Fe}}\left(\mathrm{Fe}^{2+}\right.$ ion couplers) before the unimer label: for example PZnM-Br denotes the dynamer formed from $\mathbf{M}-\mathbf{B r}$ and $\mathrm{Zn}^{2+}$ ions; $\mathbf{P}_{\mathbf{F e}} \mathbf{B}-\mathbf{N}^{+}$the dynamer formed from B- $\mathbf{N}^{+}$and $\mathrm{Fe}^{2+}$ ions, etc.

\section{Synthesis of unimers and dynamers}

Bromohexyl unimers $\mathbf{M - B r}$ and B-Br carrying 6-bromohexyl groups were prepared using the Suzuki-Miyaura coupling strategy (Scheme 1) and conditions applied earlier. ${ }^{28}$ The key monomer: 3-(6-bromohexyl)thiophene, BrHexTh, was prepared by the dropwise addition of 3-thienyllithium to a four-fold stoichiometric excess of 1,6-dibromohexane in hexane and purified by vacuum fractionation. A part of BrHexTh was transformed into corresponding 2,5-bis(borolane $)^{29,30}$ which was then reacted with Brtpy to give unimer M-Br. Another portion of BrHexTh was brominated with NBS to give 2-bromoderivative, which in the reaction with diborolane gave $3,3^{\prime}$ bis(6-bromohexyl)-2,2'-bithiophene. The latter was then transformed to bis(boronate) which, in the reaction with Brtpy, gave unimer B-Br.<smiles>[X]CCCCCCc1cc(-c2cc(-c3ccccn3)nc(-c3ccccn3)c2)sc1-c1cc(-c2ccccn2)nc(-c2ccccn2)c1</smiles><smiles>[X]CCCCCCc1cc(-c2cc(-c3ccccn3)nc(-c3ccccn3)c2)sc1-c1sc(-c2cc(-c3ccccn3)nc(-c3ccccn3)c2)c(Cl)c1CCCCCC[Y4]</smiles>

unimers $B$

$$
\begin{array}{ll}
\text { M-Br } & \mathrm{X}=\mathrm{Br} \\
\mathbf{M}^{-N^{+}} & \mathrm{X}=\mathrm{Me}_{3} \mathrm{~N}^{+}
\end{array}
$$$$
\begin{array}{ll}
\text { B-H } & \mathrm{X}=\mathrm{H} \\
\mathbf{B}-\mathrm{Br} & \mathrm{X}=\mathrm{Br} \\
\text { B-N }^{+} & \mathrm{X}=\mathrm{Me}_{3} \mathrm{~N}^{+}
\end{array}
$$
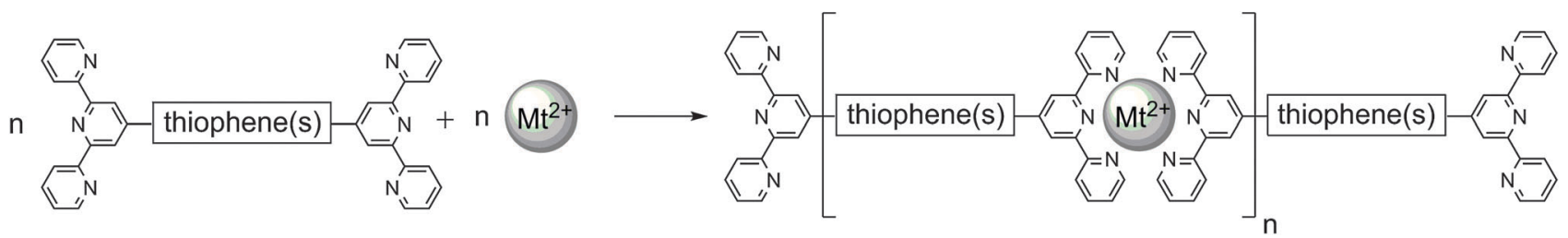

Chart 1 Structures and codes of prepared unimers and the schematic structure of the metallo-supramolecular dynamer. 


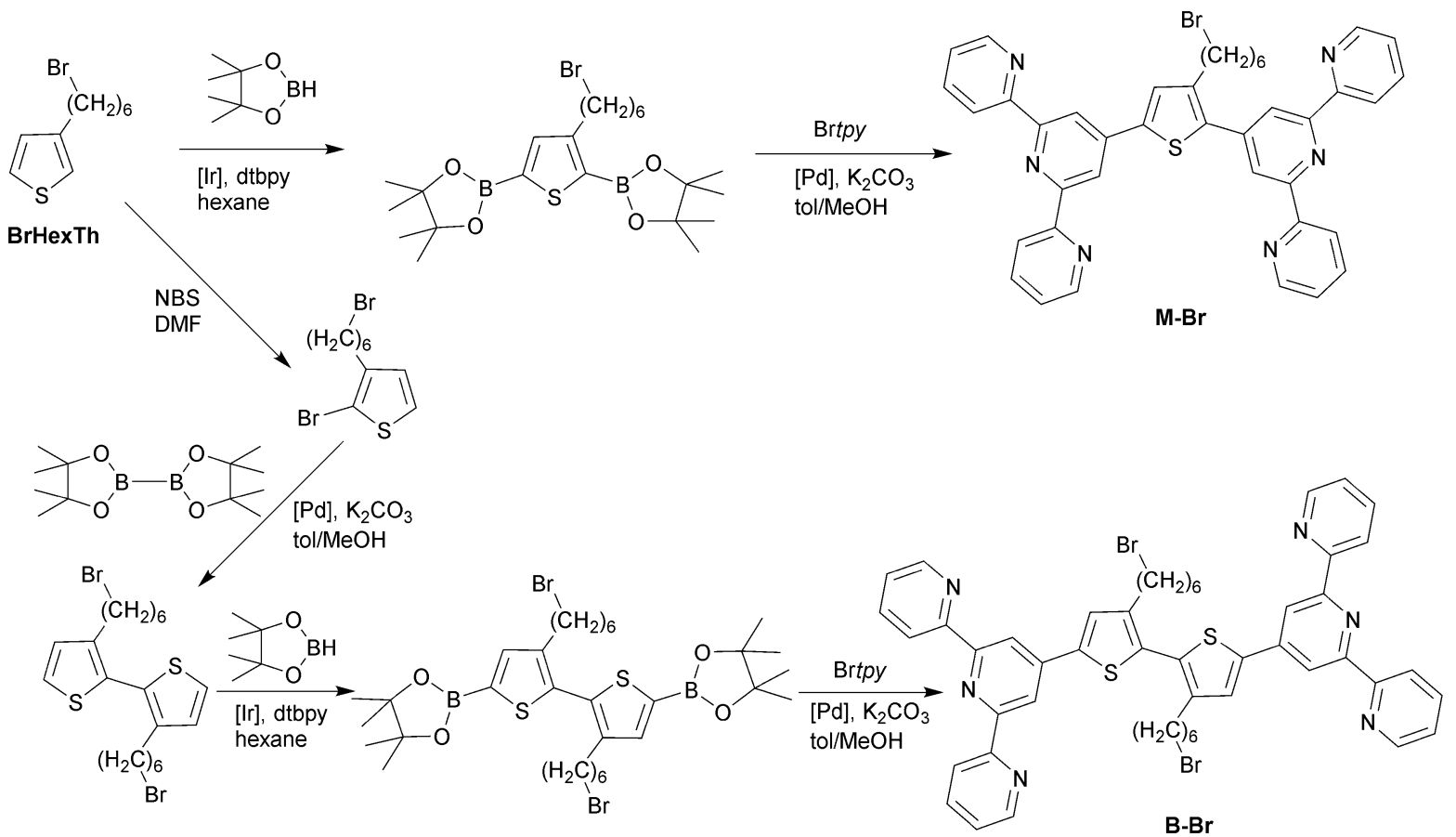

Scheme 1 Preparation of unimers $\mathbf{M}-\mathbf{B r}$ and $\mathbf{B}-\mathbf{B r}$ (precursors of ionic unimers).

Modification of bromohexyl to ionic unimers has surprisingly met serious difficulties. Originally we wanted to replace $\mathrm{Br}$ atoms with $N$-methylimidazolium groups - current cations of ionic liquids, since such modification took place easily with poly[3-(2-bromoethoxy)-4-methylthiophene, ${ }^{31,32}$ poly(BrHexTh), ${ }^{33}$ and also on BrHexTh even in the presence of free terpyridine in our preliminary experiments. However, in sharp contrast, the reaction of bromo-unimers with $\mathrm{N}$-methylimidazole did not proceed at all at laboratory temperature and, at increased temperatures (about $50{ }^{\circ} \mathrm{C}$ or higher), significant elimination of $\mathrm{HBr}$ took place that gave a considerable fraction of unsaturated hex-5-en-1-yl side groups. The $\mathrm{HBr}$ elimination appeared even under the solvent-free conditions: in solutions of $\mathbf{M}-\mathbf{B r}$ or $\mathbf{B}-\mathbf{B r}$ in $N$-methylimidazole at $70{ }^{\circ} \mathrm{C}$. Therefore, we decided to modify $\mathbf{M}-\mathbf{B r}$ or $\mathbf{B}-\mathbf{B r}$ with a stronger agent: trimethylamine $\left(\mathrm{Me}_{3} \mathrm{~N}\right)$, which has one important advantage: its stoichiometric excess is easy to remove by evaporation from the resulting reaction mixture.

The difficulties accompanying the ionization indicate that the reaction of bromohexyl unimers with $N$-methylimidazole is inhibited by tpy end-groups. The reason for it might be seen in the increased basicity of tpy end-groups due to donation of electrons from neighboring thiophene rings. Interactions between tpy and polar $-\mathrm{CH}_{2} \mathrm{Br}$ groups can be strong enough to keep these groups in close proximity. This suggests preferred macrocyclic conformations of $\mathbf{B}-\mathbf{B r}$ and $\mathbf{M}-\mathbf{B r}$ molecules since intramolecular cycles are much more resistant to the strain induced by thermal motion compared to linear supramolecular chains. Nevertheless, the intermolecular inhibition with tpy end-groups of other molecules is not excluded.

The ${ }^{1} \mathrm{H}$ NMR spectra evidenced the transformation of bromoto trimethylammonium-unimers by disappearance of the signal of the $\mathrm{CH}_{2}(-\mathrm{Br})$ group (3.38 ppm for $\mathbf{M}-\mathbf{B r}$; $3.42 \mathrm{ppm}$ for $\mathbf{B}-\mathbf{B r}$ ) and appearance of the signal of nine protons of the $\mathrm{CH}_{3}$ group in $\mathrm{Me}_{3} \mathbf{N}^{+}$groups (3.03 ppm for $\mathbf{M}-\mathbf{N}^{+} ; 3.07 \mathrm{ppm}$ for $\mathbf{B}-\mathbf{N}^{+}$). The signal of the $\mathrm{CH}_{2}$ unit linked to the $-\mathrm{N}^{+} \mathrm{Me}_{3}$ group was not seen being overlaid by the solvent signal (the spectrum taken in methanol). Neither the IR nor the off-resonance Raman spectra provided an additional clear evidence for modification of side groups since, as observed earlier, ${ }^{24}$ the bands of thiophene rings and tpy endgroups unambiguously dominate in the spectra of unimers.

Metallo-supramolecular dynamers were simply prepared by mixing solutions of a given unimer and zinc(II) or iron(II) perchlorate in the stoichiometric ratio of $1: 1$ and subsequently evaporating the solvent. Bromohexyl unimers (M-Br and $\mathbf{B}-\mathbf{B r}$ ) were assembled in the acetonitrile/chloroform ( $1 / 1$ by vol) mixed solvent while ionic unimers (M-N $\mathbf{N}^{+}$and $\left.\mathbf{B}-\mathbf{N}^{+}\right)$in methanol. The ionic unimers as well as dynamers are well soluble in alcohols and sparingly soluble in water wherein, however, the dissolving is a long-lasting process accompanied by fractionation (see ESI, $\dagger$ Fig. S1). This process is the subject of further study.

\section{Optical spectra of unimers and dynamers}

The UV/vis absorption spectra of all unimers are very similar each showing a flat band at $280-284 \mathrm{~nm}$, contributed with transitions in tpy end groups, and a band at wavelength $\lambda_{\mathrm{A}}=$ $336 \mathrm{~nm}$ (solutions) or $345 \mathrm{~nm}$ (films) belonging to transitions from HOMO that is spread over thiophene rings and central rings of tpy groups (Table 1 and ESI, $\dagger$ Fig. S2). The spectra are similar to the spectrum of B-H (unimer with unsubstituted hexyl side groups, $\left.\lambda_{\mathrm{A}}=339 \mathrm{~nm}\right){ }^{24}$

Close similarity of the UV/vis spectra of $\mathbf{B r}-$ and $\mathbf{N}^{+}$-unimers is not surprising since the side end-groups are quite distant 
Table 1 Spectroscopic characteristics of the prepared unimers and dynamers

\begin{tabular}{|c|c|c|c|c|c|c|}
\hline \multirow[b]{3}{*}{ Sample } & \multirow{2}{*}{\multicolumn{2}{|c|}{$\frac{\text { UV/vis absorption }}{\lambda_{\mathrm{A}}(\mathrm{nm})}$}} & \multirow{2}{*}{\multicolumn{2}{|c|}{$\begin{array}{l}\text { Luminescence } \\
\lambda_{\mathrm{F}}(\mathrm{nm})(\phi, \%)\end{array}$}} & \multirow{2}{*}{\multicolumn{2}{|c|}{$\begin{array}{l}\frac{\text { Stokes shift }}{\nu\left(\mathrm{cm}^{-1}\right)} \\
\end{array}$}} \\
\hline & & & & & & \\
\hline & Solution & Film & Solution & Film & Solution & Film \\
\hline \multicolumn{7}{|l|}{ Unimers } \\
\hline $\mathbf{M}-\mathbf{B r}$ & 335 & 344 & $406(3 \%)$ & $543(7 \%)$ & 5200 & 10650 \\
\hline $\mathbf{M}-\mathbf{N}^{+}$ & 334 & 347 & $404(3 \%)$ & $461(7 \%)$ & 5200 & 7150 \\
\hline B-Br & 338 & 344 & $452(5 \%)$ & $561(4 \%)$ & 7450 & 11250 \\
\hline $\mathbf{B}-\mathbf{N}^{+}$ & 337 & 346 & $450(5 \%)$ & $519(3 \%)$ & 7450 & 9650 \\
\hline $\mathbf{B}-\mathbf{H}^{a}$ & 339 & $\begin{array}{l}400-420 \\
450_{\mathrm{sh}}\end{array}$ & $450(3 \%)$ & 550 & 7280 & $\sim 6000$ \\
\hline
\end{tabular}

Zn-dynamers

\begin{tabular}{lllllll}
$\mathbf{P}_{\text {Zn M-Br }}$ & 380 & 407 & 440 & $460(3 \%)$ & 3600 & 2850 \\
$\mathbf{P}_{\text {Zn }} \mathbf{M}-\mathbf{N}^{+}$ & 370 & 393 & 444 & $473(1 \%)$ & 4500 & 4300 \\
$\mathbf{P}_{\text {Zn B-Br }}$ & 385 & 396 & 550 & $525(4 \%)$ & 7800 & 6200 \\
$\mathbf{P}_{\text {Zn B-N }} \mathbf{B}^{+}$ & 375 & 392 & 550 & $538(3 \%)$ & 8500 & 6900 \\
$\mathbf{P}_{\text {Zn }} \mathbf{B}-\mathbf{H}^{a}$ & 390 & 391 & 535 & 545 & 6950 & 7230 \\
\hline \multicolumn{7}{c}{$\left(\lambda_{\text {MLCT }}\right)$} \\
\hline
\end{tabular}

\begin{tabular}{lll}
\hline & $\left(\lambda_{\text {MLCT }}\right)$ & $\left(\lambda_{\text {MLCT }}\right)$ \\
\hline Fe-dynamers & & \\
$\mathbf{P}_{\mathbf{F e}} \mathbf{M}-\mathbf{B r}$ & 325,373 & 394 \\
& $(590)$ & $(608)$ \\
$\mathbf{P}_{\mathbf{F e}} \mathbf{M}-\mathbf{N}^{+}$ & 325,370 & 388 \\
& $(588)$ & $(601)$ \\
$\mathbf{P}_{\mathbf{F e}} \mathbf{B}-\mathbf{B r}$ & 322,370 & 386 \\
& $(594)$ & $(598)$ \\
$\mathbf{P}_{\mathbf{F e}} \mathbf{B}-\mathbf{N}^{+}$ & 320,366 & 380 \\
& $(591)$ & $(598)$
\end{tabular}

${ }^{a}$ Data for solutions measured in THF taken from ref. 24 .

from main chains. On the other hand, close similarity of the absorption spectra of $\mathbf{M}$ - and $\mathbf{B}$-unimers is not obvious regarding the different numbers of thiophene rings in their chains. The reason for it is a high dihedral angle $\left(c a .67^{\circ}\right)^{24}$ of the thiophene-tothiophene bond in B-molecules (due to steric hindrances of side chains - see Chart 1), which greatly reduces the delocalization of electrons in $\mathbf{B}$ chains. Therefore, B-type molecules absorb light like two almost independent 4 '-(thiophen-2-yl)terpyridine species.

The tiny difference ( 6 to $13 \mathrm{~nm}$ ) between absorption maxima observed for solutions and films proves a negligible effect of the molecular packing on the light absorption by the studied unimers. Particularly interesting is the conformity of UV/vis spectra taken from solutions $(\sim 338 \mathrm{~nm})$ and films $(345 \pm 1 \mathrm{~nm})$ of $\mathbf{B}-\mathbf{B r}$ and $\mathbf{B}-\mathbf{N}^{+}$. The parent unimer, B-H, namely shows considerable red shift when going from solution $(339 \mathrm{~nm})$ to film (410 nm with a shoulder at $450 \mathrm{~nm}$ ), which proves substantial planarity of B-H molecules in the film. ${ }^{24}$ Thus the conformity of the solution and solid-state absorption spectra proves to non-planar conformations of $\mathbf{B}-\mathbf{B r}$ and $\mathbf{B}-\mathbf{N}^{+}$molecules in films. This can be explained by the above-proposed supramolecular macrocyclic conformations of polar and ionic B-type molecules, which stabilizes the crossing thiophene ring planes. As mentioned above, the disorder owing to analogous intermolecular interactions cannot be excluded. Anyway, these spectral features are consistent with the suggested explanation of the inhibitive effect of tpy end groups in ionization of bromo-precursors.

Unlike the UV/vis absorption, the luminescence emission of B-unimers $\left(\lambda_{\mathrm{F}}=450 \mathrm{~nm}\right)$ in solutions is significantly red shifted compared to M-unimers $\left(\lambda_{\mathrm{F}}=405 \mathrm{~nm}\right.$, ESI, $\dagger$ Table S1), obviously due to the transition of excited B-molecules to lowered-energy conformations with coplanar quinoidal rings and thus more delocalized $\pi$-electrons, from which the light emission takes place. The extent of the excited state relaxation of molecules in the solid state is higher than that observed for dissolved molecules as evidenced by the Stokes shift values (Table 1). The lowered extent of relaxation observed for the ionic $\mathbf{N}^{+}$-type unimers can be attributed to limitations originating from more intense electrostatic interactions.

Absorption spectra of dynamers show the longest wavelength bands red shifted about 30 to $65 \mathrm{~nm}$ with respect to the corresponding free unimer, the shift being higher for Br-compared to $\mathbf{N}^{+}$-dynamers and for $\mathrm{Zn}$-compared to Fe-dynamers. Spectra of Fe-dynamers show an extra band at ca. $600 \mathrm{~nm}$ (wavelength $\left.\lambda_{\text {MLCT }}\right)$, which is typical of $(t p y)_{2} \mathrm{Fe}^{2+}$ grouping ${ }^{34}$ and is contributed by electronic transitions within the metal to ligand charge transfer (MLCT) complex. As usual, Zn-dynamers derived from $(t p y)_{2}$ oligomers show luminescence emission while Fe-dynamers do not. The absence of luminescence for $\mathrm{Fe}(\mathrm{II})$-dynamers (complexes) is attributed to the fact that their lowest excited state is a d-d triplet state that is very close to the ground state. ${ }^{35}$ As the potential $d-d$ phosphorescence is spin forbidden, the $\mathrm{d}-\mathrm{d}$ triplet state easy depletes the upper excited states and decays by unambiguously preferred non-radiative transitions in accord with the energy gap law. ${ }^{36,37}$

The luminescence emission bands of the solid $\mathbf{P}_{\mathbf{Z n}} \mathbf{M}$ dynamers (467 $\pm 7 \mathrm{~nm}$ ) are located close to each other as well as the bands of $\mathbf{P}_{\mathbf{Z n}} \mathbf{B}$-dynamers (532 $\pm 7 \mathrm{~nm}$ ). Interestingly, the bands of dissolved dynamers: $442 \pm 2 \mathrm{~nm}$ for $\mathbf{P}_{\mathbf{Z n}} \mathbf{M}$ - and $550 \mathrm{~nm}$ for $\mathbf{P}_{\mathbf{Z n}} \mathbf{B}$-dynamers are not too distant from the bands of solid dynamers. This indicates that the conformational disorder of the dynamer chains in a film is comparable to their disorder in solution.

\section{Raman spectra of dynamers}

Because Fe-dynamers do not emit luminescence, it was possible to acquire their resonance as well as off-resonance Raman spectra using excitation wavelengths $\left(\lambda_{\mathrm{ex}}\right)$ across the whole visible region $\left(\lambda_{\text {ex }}=445,532,633\right.$ and $\left.780 \mathrm{~nm}\right)$. In contrast, the spectra of $\mathrm{Zn}$ dynamers were measurable only in the off-resonance mode $\left(\lambda_{\mathrm{ex}}=780 \mathrm{~nm}\right)$ since luminescence dominated the spectra collected with excitations at all other $\lambda_{\mathrm{ex}}$.

Off-resonance Raman spectra of Zn-dynamers (Fig. 1) are similar to each other. Each shows a medium to low intensity band of coordinated tpy groups: (i) ring-stretching modes at 1610 to $1600 \mathrm{~cm}^{-1}, 1570 \mathrm{~cm}^{-1}$ and 1535 to $1548 \mathrm{~cm}^{-1}$, (ii) in plane deformation mode at $1288 \mathrm{~cm}^{-1}$, and (iii) asymmetric ring breathing mode at about $1025 \mathrm{~cm}^{-1} \cdot{ }^{38,39}$ However, the strongest bands in these spectra are bands of thiophene-2,5-diyl units, ${ }^{33,40-43}$ which appeared at 1484, 1450 and $1405 \mathrm{~cm}^{-1}$ for $\mathbf{P}_{\mathbf{Z n}} \mathbf{M}$-type dynamers, and at 1484, 1457 and 1411 to $1417 \mathrm{~cm}^{-1}$ for $\mathbf{P}_{\mathbf{Z n}} \mathbf{B}$-type dynamers. Different end-capping of hexyl-groups has very little impact on the spectral pattern. Thus it can be concluded that the spectral differences primarily stem from different numbers of thiophene rings in unimeric units. 


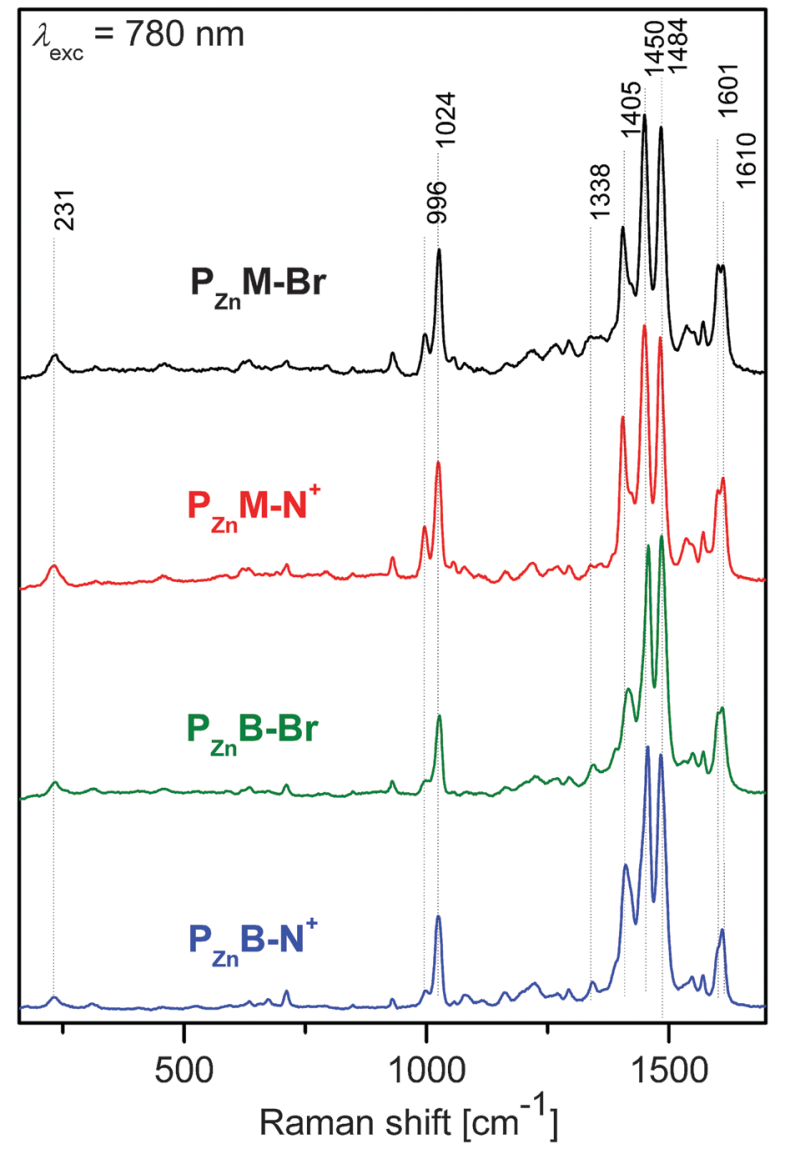

Fig. 1 Off-resonance Raman spectra of Zn-dynamers.

Compared to the spectra of Zn-dynamers, the off-resonance Raman spectra $\left(\lambda_{\text {ex }}=780 \mathrm{~nm}\right)$ of Fe-dynamers (Fig. 2) show a more intense (and not split into doublet) band of coordinated tpy groups at $1610 \mathrm{~cm}^{-1}$, blue-shift of the tpy ring-breathing mode band to $1039 \mathrm{~cm}^{-1}$, relatively strong band at $1288 \mathrm{~cm}^{-1}$ that should also be attributed to tpy groups ${ }^{38}$ and somewhat different patterns of bands attributable to thiophene-rings (1478 to $1345 \mathrm{~cm}^{-1}$ ). It should be mentioned here that the band at $1478 \mathrm{~cm}^{-1}$ is most probably also contributed with transitions in tpy groups coordinated to $\mathrm{Fe}^{2+}$ ions since Raman spectra of $\left[\mathrm{Fe}(\text { terpyridine })_{2}\right]^{2+}$ species show a strong band at $1472 \mathrm{~cm}^{-1} \cdot{ }^{38}$ As can be seen, the spectral differences between $\mathbf{P}_{\mathbf{F e}} \mathbf{M}$-type and $\mathbf{P}_{\mathbf{F e}} \mathbf{B}$-type dynamers are more pronounced compared to differences between their $\mathrm{Zn}$ counterparts.

Raman spectra of Fe-dynamers taken with different $\lambda_{\text {ex }}$ are compared in Fig. 2. The spectra of the given dynamer differ from each other because each excitation line selectively, resonantly enhances Raman bands of chromophore(s) absorbing at $\lambda_{\text {ex }}$ (ESI, $\uparrow$ Fig. S2). Thus the Raman spectra can help to identify chromophore(s) contributing to the respective absorption bands.

Raman spectra taken with $\lambda_{\text {ex }}=445 \mathrm{~nm}$ showed strong peaks typical of thiophene rings but weak peaks characteristic of tpy groups. Moreover, the intensity difference between the tpy and thiophene Raman bands of $\mathbf{P}_{\mathbf{F e}} \mathbf{B}$-dynamers is much higher than in the case of $\mathbf{P}_{\mathbf{F e}} \mathbf{B}$-dynamers, which obviously reflects a higher number of thiophene rings in the B-type repeating units. Hence it follows that the broad UV/vis band at about $400 \mathrm{~nm}$ is mainly contributed with electronic transitions between orbitals spread over the axis of a unimer unit that comprises thiophene ring(s).

The excitation at $\lambda_{\text {ex }}=532 \mathrm{~nm}$ matches the blue arm of the MLCT band (600 nm). Raman spectra of Fe-dynamers taken with this excitation are the only ones in which overtones and combination bands are observable in the region from $2200-3200 \mathrm{~cm}^{-1}$. Peaks at 1610, 1562, 1537, 1470, 1347 and $1288 \mathrm{~cm}^{-1}$ unambiguously dominate the finger-print region of all these resonance Raman spectra, while bands typical of thiophene rings are weak (Fig. 2). Minor spectral differences between the $\mathbf{M}$-type and B-type Fe-dynamers are seen in the position of a weak band at $1396 \mathrm{~cm}^{-1}$ (M-type) vs. $1408 \mathrm{~cm}^{-1}$ (B-type) and the presence of a triplet at 682,673 and $652 \mathrm{~cm}^{-1}$ (M-type) but only a doublet at 681 and $653 \mathrm{~cm}^{-1}$ (B-type) in the corresponding spectra. Nevertheless, these differences are quite low and do not disturb the high similarity of spectral patterns. This extremely large consensus in the spectral patterns is in full concordance with the excitation into the MLCT band of $-t p y-\mathrm{Fe}^{2+}-t p y$ - linkages. However, these spectral patterns significantly differ from the spectral pattern of the resonance Raman spectrum of the $\left[\mathrm{Fe}(\text { terpyridine })_{2}\right]^{2+}$ complex taken with the same excitation: $\lambda_{\text {ex }}=532 \mathrm{~nm} .{ }^{35}$ This clearly proves that the MLCT state is localized not only on the directly coordinated tpy units but also on thiophene unit(s) that are more distant from the coordination centre.

Raman spectra taken with $\lambda_{\mathrm{ex}}=633 \mathrm{~nm}$, despite that this line well matches the red arm of the MLCT band, show similar spectral patterns as off-resonance spectra taken with $\lambda_{\text {ex }}=780 \mathrm{~nm}$. Small differences are mainly (i) lowered intensity of the doublet (M-type) and triplet (B-type) in the range of $1345-1478 \mathrm{~cm}^{-1}$ and (ii) increased intensity of the bands at $345 \mathrm{~cm}^{-1}$ and in the region from 650 to $800 \mathrm{~cm}^{-1}$. These spectra also differ in the intensity of the band of ring breathing mode $\left(1039 \mathrm{~cm}^{-1}\right)$. However, this band shows rather exceptional trend for all excitations: continuous amplification with increasing $\lambda_{\mathrm{ex}}$, the trend that has been reported for Raman spectra of various $\left[\mathrm{Ru}^{\mathrm{II}}(b p y)_{3}\right]^{2+}$ complexes (bpy is $2,2^{\prime}$-bipyridine $)^{38,44-46}$ and has remained unexplained.

Important observation is that overtones and combined bands are absent in the spectra excited at $633 \mathrm{~nm}$ and their spectral patterns substantially differ from the pattern of spectra excited at $532 \mathrm{~nm}$ (Fig. 2). Regarding that both these excitation lines match the MLCT band, one can conclude that the MLCT electronic absorption band of dynamers consists of several different electron transitions of different symmetry.

\section{Assembly of unimers to metallo-supramolecular dynamers}

Assembly of dynamers from unimers and metal ions $\left(\mathrm{Mt}^{2+}\right)$ in solutions (acetonitrile/chloroform 1/1 by vol. for Br-type and methanol for $\mathbf{N}^{+}$-type unimers and dynamers) was studied more in detail using the UV/vis and fluorescence spectroscopy, viscometry and size exclusion chromatography (SEC).

For spectroscopic studies, a set of solutions of the constant unimer concentration $\left(2 \times 10^{-5} \mathrm{M}\right)$ and stepwise increasing of the ions-to-unimer mole ratio $\left(\left[\mathrm{Mt}^{2+}\right] /[\mathrm{U}]=r\right.$ from 0 to 3$)$ was prepared for each unimer - ions couple. The solutions were 


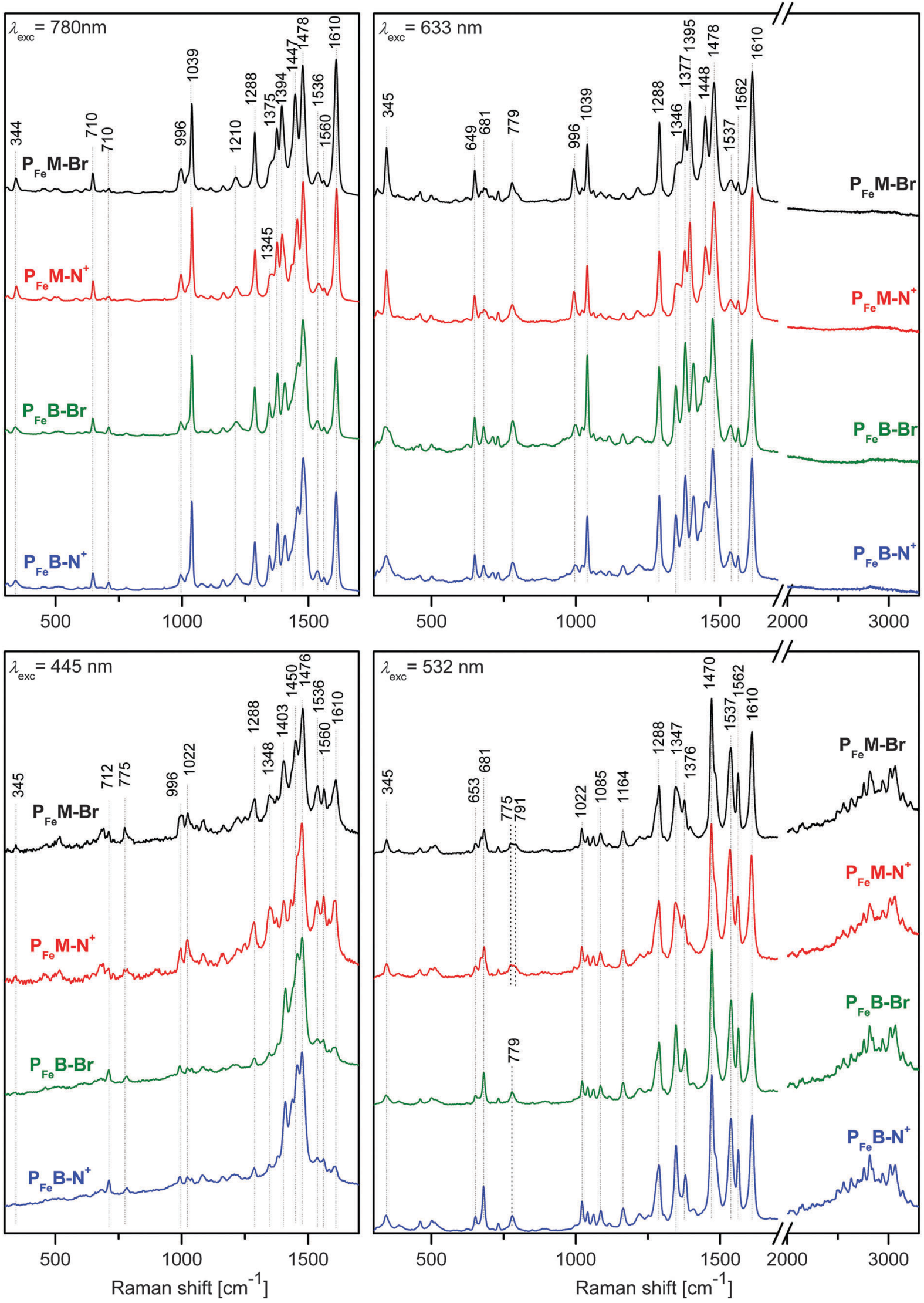

Fig. 2 Resonance and off-resonance Raman spectra of Fe-dynamers. 

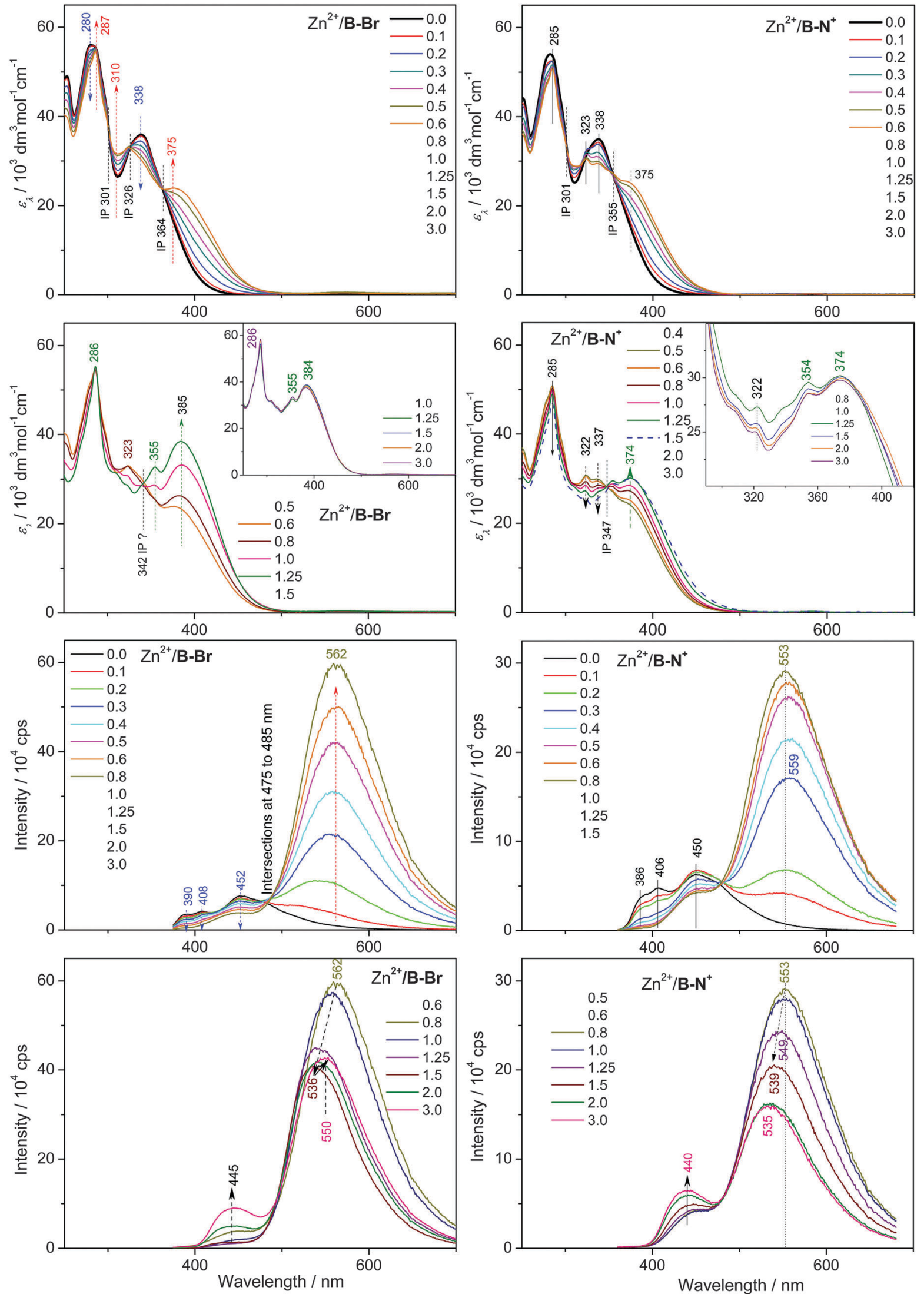

Fig. 3 Changes in UV/vis and photoluminescence spectra accompanying titration of $\mathbf{B}-\mathbf{B r}$ (left) and $\mathbf{B}-\mathbf{N}^{+}$(right) unimers with $\mathrm{Zn}^{2+}$ ions. Initial unimer concentration $2 \times 10^{-5} \mathrm{~mol} \mathrm{dm}^{-3}$; chloroform/acetonitrile (Br-unimers), methanol ( $\mathbf{N}^{+}$-unimers), room temperature. 

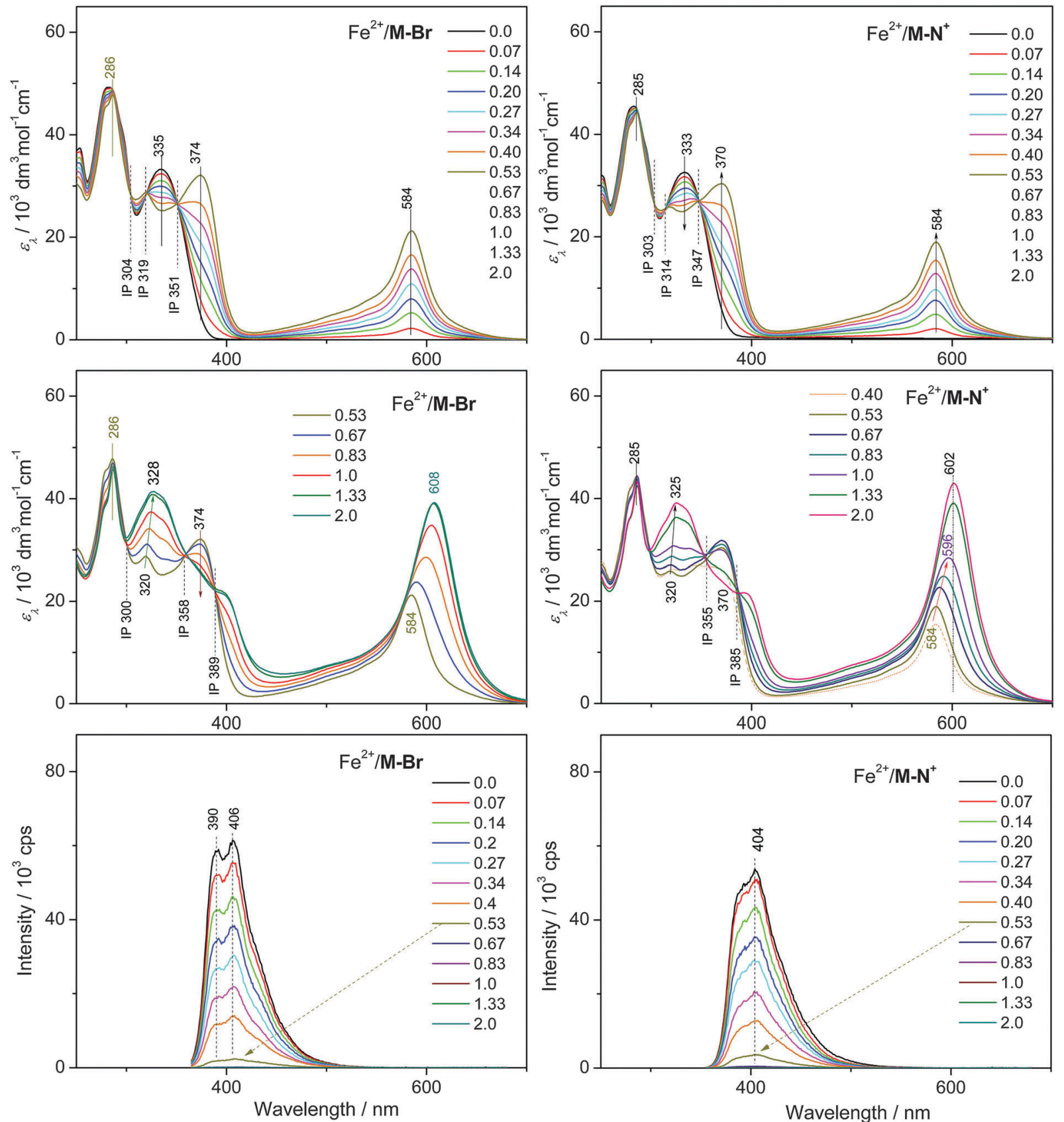

Fig. 4 Changes in UV/vis and photoluminescence spectra accompanying titration of $\mathbf{B}-\mathbf{B r}$ (left) and $\mathbf{B}-\mathbf{N}^{+}$(right) unimers with Fe ${ }^{2+}$ ions. Initial unimer concentration $2 \times 10^{-5} \mathrm{~mol} \mathrm{dm}^{-3}$; chloroform/acetonitrile ( $\mathbf{B r}$-unimers), methanol ( $\mathbf{N}^{+}$-unimers), room temperature.

allowed to equilibrate for 24 hours prior to measuring of their $\mathrm{UV} / \mathrm{vis}$ and luminescence spectra. Changes in the spectra with the stepwise increasing composition ratio $r$ are shown in Fig. 3 and 4 and ESI, $\dagger$ Fig. S5 and S6. The UV/vis and luminescence spectral sets are each presented in two figures (except for luminescence spectra of systems with $\mathrm{Fe}^{2+}$ ions) in order to show breaks in the development trend, which indicates existence of different stages of assembling. The first break in the trend appeared at $r$ slightly above 0.5 , the second one, if present, at $r>1.0$.

The first stage of assembling ( $r$ from 0 to $c a$. 0.6) is reflected in the UV/vis spectra by: (i) a small change of the band shape at about $280 \mathrm{~nm}$ resulting in the shift of its apex to $c a .287 \mathrm{~nm}$, (ii) the attenuating band at about $336 \mathrm{~nm}$ that is typical of the free unimer, and (iii) the appearance of a new band at 370-380 nm. The spectral set of each $\mathrm{Mt}^{2+} / \mathrm{U}$ system shows two to three isosbestic points (IP), the presence of which indicates transformation of defined free unimer species into another defined species. The stoichiometry says that the newly formed species should be "butterfly dimer" species U-Mt ${ }^{2+}-\mathrm{U}$.

Complementary luminescence spectra of $\mathrm{Zn}^{2+} / \mathrm{U}$ systems ( $r$ from 0 to $c a$. 0.6, Fig. 3, ESI, $\dagger$ Fig. S5) show a gradually attenuating band of free unimers and a simultaneously growing 
new band of coordinated unimer species. Each spectral set shows one IP, thus supporting the idea on the prevailing formation of dimers. On the other hand, luminescence spectra of $\mathrm{Fe}^{2+} / \mathrm{U}$ systems exhibit only gradually attenuated luminescence to its complete quenching at $r>0.6$. However, it clearly demonstrates disappearance of free unimer species from solution at $r>0.6$, and thus as well suggests their preferred conversion to butterfly dimers.

Electronic spectra monitored at $r$ above 0.6, do not pass through IPs characteristic of the first stage, which indicates transition to the second stage of assembly where dynamer chains should grow. Unlike the first stage of assembly, the development of spectral patterns during the second stage is strongly influenced by the structure of unimers. Differences are mainly seen in: (i) the extent of amplification of the UV/vis band at $370-380 \mathrm{~nm}$, (ii) the presence or absence of new IPs, and (iii) spectral patterns in the region from 300 to $400 \mathrm{~nm}$. A direct correlation of the observed differences to the structure of dynamers is not apparent. Nevertheless, all these spectra show either a change in the development trend or almost conservation of the spectral pattern at ratios $r$ above 1.25 , which indicates occurrence of the third assembly stage (see Fig. 5 showing the dependence of $\lambda_{\text {MLCT }}$ on $r$ ).

The third stage of assembly should consist of the end-capping of dynamer chains with $\mathrm{Mt}^{2+}$ ions and depolymerization of the chains to the shorter, also end-caped ones. The reaction of a bis(tpy) $\mathrm{Zn}^{2+}$ species with a free $\mathrm{Zn}^{2+}$ ion yielding two (tpy) $\mathrm{Zn}^{2+}$ species is well known. ${ }^{4-49}$ A similar reaction of bis $(t p y) \mathrm{Fe}^{2+}$ species, particularly species with monotopic ligands, is not so obvious, ${ }^{47,50}$ however, it was reported to take place in the case of metallo-supramolecular polymers. ${ }^{48,51}$

In order to examine whether this process takes place in solutions of our conjugated dynamers we carried out a viscometric study on the $\mathrm{Fe}^{2+} / \mathbf{M}-\mathrm{Br}$ system (see results in Fig. 6). As can be seen, the dependence of the relative viscosity $\left(\eta_{\mathrm{r}}\right)$ of $\mathbf{M - B r}$ solutions $(0.5 \mathrm{mM})$ in $\mathrm{CHCl}_{3} / \mathrm{CH}_{3} \mathrm{CN}(1: 1)$ on the ratio $r$ passes through maximum at $r=1$ and then decreases. This indicates that the longest $\mathbf{P}_{\mathbf{F e}} \mathbf{M}-\mathbf{B r}$ chains are obtained at $r=1$ and that these chains most probably depolymerize at $r>1$. Depolymerization should give the chains end-capped with $\mathrm{Fe}^{2+}$ ions.

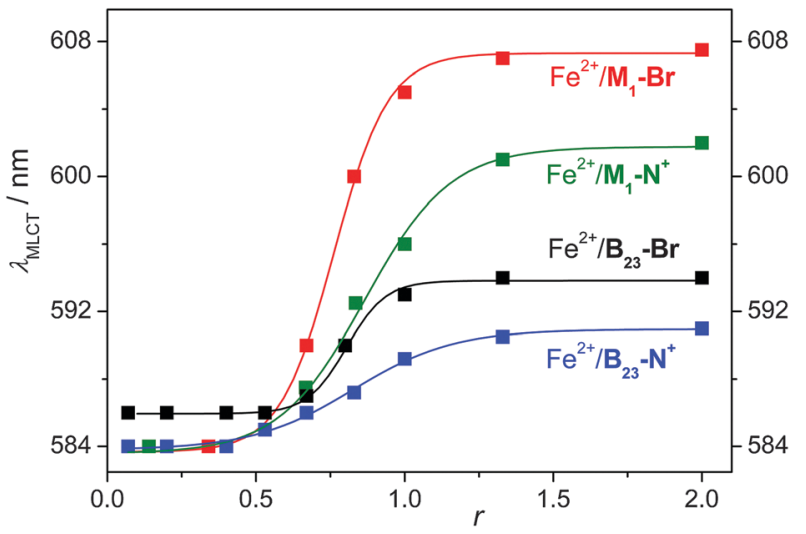

Fig. 5 The wavelength of MLCT bands of systems with $\mathrm{Fe}^{2+}$ ions as a function of the system composition.

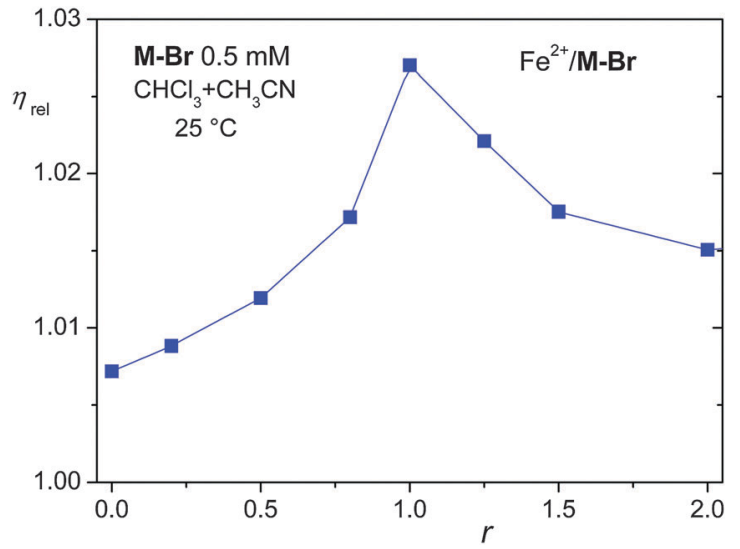

Fig. 6 Relative viscosity of solutions of the system $\mathrm{Fe}^{2+} / \mathrm{M}-\mathrm{Br}$ as a function of composition.

Assembling of unimers to dynamers was further studied using the SEC instrument equipped with a diode-array UV/vis detector (DAD). Mixed solutions of $\mathbf{M}-\mathrm{Br}(0.5 \mathrm{mM})$ and $\mathrm{Zn}^{2+}$ or $\mathrm{Fe}^{2+}$ ions ( $r$ from 0 to 2.0 ) in $\mathrm{CHCl}_{3} / \mathrm{CH}_{3} \mathrm{CN}(1: 1)$ mixed solvent were allowed to equilibrate for one day and then injected into the SEC system. The same mixed solvent containing $\mathrm{Bu}_{4} \mathrm{~N}^{+} \mathrm{PF}_{6}{ }^{-}$ (to suppress aggregation) was used as a mobile phase.

The SEC records of the $\mathrm{Zn}^{2+} / \mathbf{M}-\mathrm{Br}$ systems showed peaks of only free unimer $\mathbf{M}-\mathbf{B r}$, which proves a rapid complete dissociation of $\mathbf{P}_{\mathbf{Z n}} \mathbf{M}$-Br chains due to multifold dilution of the solution inside columns (injected $20 \mu \mathrm{L}$, elution volume of $37 \mathrm{~mL}$ ). This proves that $\mathbf{P}_{\mathbf{Z n}} \mathbf{M}-\mathbf{B r}$ chains are supramolecular systems with rapid constitutional dynamics. In contrast, the $\mathrm{Fe}^{2+} / \mathbf{M}-\mathbf{B r}$ systems provided the SEC records typical of polymers, with the resolution decreasing with increasing ratio $r$ (Fig. 7a). The DAD (i.e., UV/vis) spectra of SEC fractions showed the dependence of the spectral patterns on the elution time $\left(t_{\mathrm{el}}\right)$ : the patterns typical of long dynamer chains for short $t_{\mathrm{el}}$ and typical of butterfly dimers for long $t_{\mathrm{el}}$ (Fig. 7b). This proves that $\mathbf{P}_{\mathbf{F e}} \mathbf{M}$-Br chains are the metallo-supramolecular systems with slow constitutional dynamics. As can be seen, well resolved SEC records were obtained only for systems with $r<1$. The systems with $r \geq 1$ gave poorly resolved SEC records with the area below the elution curve decreasing with increasing value of $r$, which proves to retention of chains in SEC columns. The detained $\mathbf{P}_{\mathbf{F e}} \mathbf{M}-\mathbf{B r}$ chains are obviously the chains end-capped with $\mathrm{Fe}^{2+}$ ions; they had to be additionally washed out with $2,2^{\prime}$-bipyridine.

The DAD spectra of SEC-fractions $\left(t_{\mathrm{el}}=1350 \mathrm{~s}\right)$ of the systems with $r<1$ (Fig. 8) are identical with the dilute solution $(0.02 \mathrm{mM})$ spectrum of dimers. If this SEC peak is assigned to dimers, peak at $1273 \mathrm{~s}$ to trimers, etc. (Fig. 7a), the peak assignment provides linear semi-log dependence of the degree of polymerization $(X)$ of $\mathbf{P}_{\mathbf{F e}} \mathbf{M}-\mathbf{B r}$ chains on $t_{\mathrm{el}}$ for systems with $r<1$ (ESI, $\dagger$ Fig. S7). Average values of $X$ calculated from the SEC records using this calibration are listed in Table 2. The used peak assignment is supported by the DAD spectra of higher- $X$ SEC-fractions, which correspond to dilute solution spectra of higher oligomers.

The presence of higher- $X$ fractions in $\mathrm{Fe}^{2+} / \mathbf{M}-\mathrm{Br}$ solutions with fairly understoichiometric ratios, $r=0.2$ and 0.5 , should be 

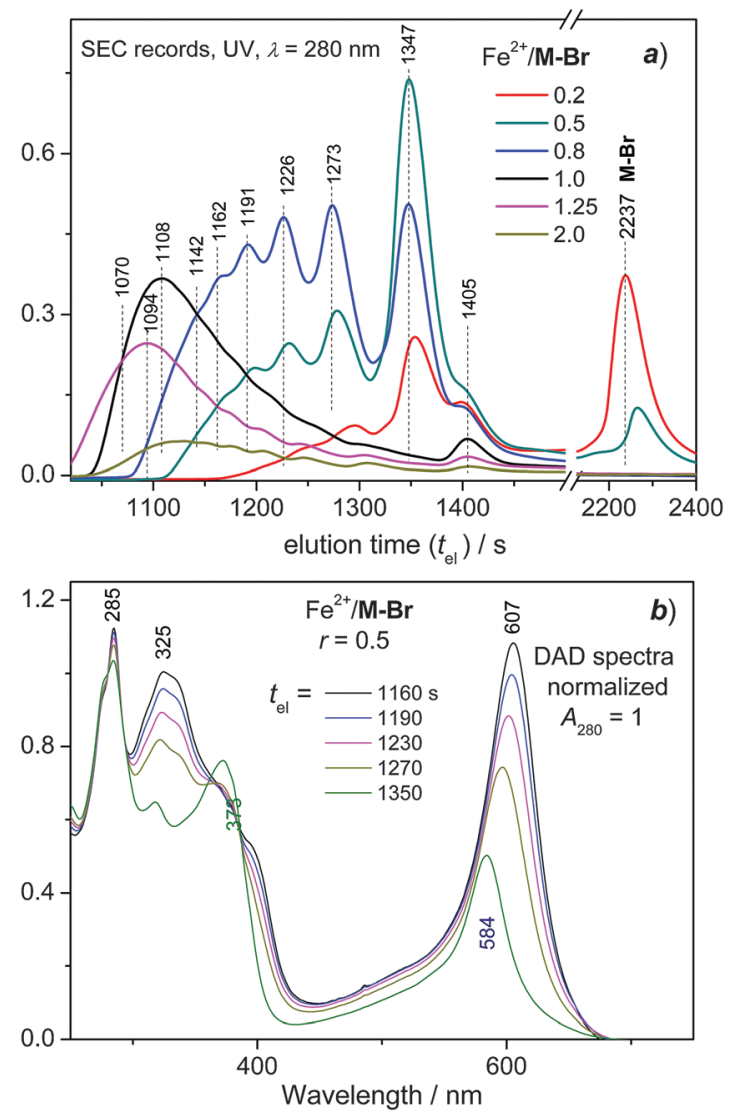

Fig. 7 The SEC records of $\mathrm{Fe}^{2+} / \mathrm{M}-\mathrm{Br}$ systems of different composition (a) and DAD spectra at different elution time $t_{\mathrm{el}}$ (b).

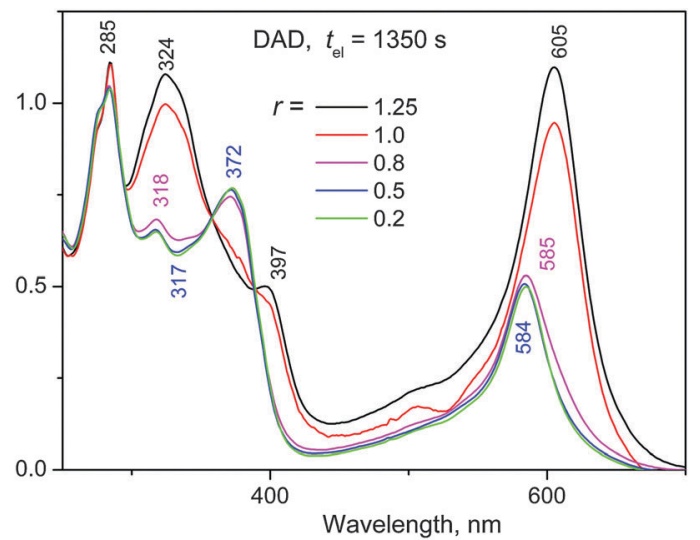

Fig. 8 The UV/vis spectra of SEC fractions $\left(t_{\mathrm{el}}=1350 \mathrm{~s}\right)$ of $\mathrm{Fe}^{2+} / \mathrm{M}-\mathrm{Br}$ systems of different composition.

Table 2 Number-average $\left(X_{n}\right)$ and weight-average $\left(X_{w}\right)$ degrees of polymerization of $\mathbf{P}_{\mathrm{Fe}} \mathrm{M}-\mathrm{Br}$ in solution calculated from SEC records

\begin{tabular}{llll}
\hline$r$ & $X_{\mathrm{n}}$ & $X_{\mathrm{w}}$ & $D$ \\
\hline 0.2 & 2.26 & 2.46 & 1.09 \\
0.5 & 2.62 & 3.10 & 1.18 \\
0.8 & 3.31 & 4.04 & 1.22 \\
1 & 5.43 & 6.62 & 1.22 \\
1.25 & 5.94 & 7.48 & 1.26
\end{tabular}

ascribed to the effect of transiently locally increased concentration during mixing of more concentrated solutions of $\mathbf{M}-\mathbf{B r}$ and $\mathrm{Fe}^{2+}$ ions. Formation of dynamer chains is surely a kinetically controlled process which, when mixing twenty five times more concentrated solutions ( $0.5 \mathrm{mM}$ instead $0.02 \mathrm{mM}$ ) should be $c a$. 625 times faster, thus giving rise to a high number of longer chains. As the constitutional dynamics of $\mathbf{P}_{\mathbf{F e}} \mathbf{M}-\mathbf{B r}$ is slow, the initially formed longer chains do not dissociate within one day. On the other hand, the dynamics slowness is lucky since it at all allows SEC analysis of Fe-dynamers (in contrast to Zn-dynamers).

\section{Experimental section}

\section{Materials}

n-Butyllithium (n-BuLi, 2.5 $\mathrm{M}$ in hexane), 3-bromothiophene, $N$-bromosuccinimide (NBS), bis(1,5-cyclooctadiene)di- $\mu$-methoxydiiridium(I) ([Ir(OMe)(COD) $]_{2}$ ), 4,4-di-tert-butyl-2,2-dipyridyl (dtbpy), 4,4,5,5-tetramethyl-1,3,2-dioxaborolane (HBpin), [1,3-bis(2,6diisopropylphenyl)imidazol-2-ylidene](3-chloropyridyl)palladium(II) dichloride (Peppsi-IPr), bis(pinacolato)diboron $\left(\mathrm{B}_{2} \mathrm{pin}_{2}\right)$, trimethylamine (4.2 $\mathrm{M}$ solution in ethanol), zinc perchlorate hexahydrate and iron(II) perchlorate hydrate (all Aldrich), $\mathrm{K}_{2} \mathrm{CO}_{3}, \mathrm{MgSO}_{4}$ (Lachner) and 4-bromo-2,2:62-terpyridine (TCI) were used as received. Hexane (Lachner) was stored over a molecular sieve, tetrahydrofurane (Aldrich) was distilled from LiAlH before use, toluene (Lachner) was distilled from sodium/benzophenone before use, methanol (Aldrich) was bubbled with argon before use, dichloromethane, chloroform (Lachner) and acetonitrile were used as obtained.

\section{Measurements}

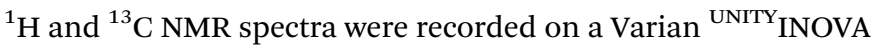
400 or Varian SYSTEM 300 instruments in $d_{8}$-THF, $d_{2}-\mathrm{CD}_{2} \mathrm{Cl}_{2}$, $d-\mathrm{CDCl}_{3}$ or $d_{4}-\mathrm{CD}_{3} \mathrm{OD}$ and referenced to the solvent signal: $7.25 \mathrm{ppm}\left(d-\mathrm{CDCl}_{3}\right), 5.32 \mathrm{ppm}\left(d_{2}-\mathrm{CD}_{2} \mathrm{Cl}_{2}\right), 3.58 \mathrm{ppm}\left(d_{8}-\mathrm{THF}\right)$ or $3.31 \mathrm{ppm}\left(d_{4}-\mathrm{CD}_{3} \mathrm{OD}\right)$ for ${ }^{1} \mathrm{H}$ and $77.0 \mathrm{ppm}\left(d-\mathrm{CDCl}_{3}\right), 53.84 \mathrm{ppm}$ $\left(d_{2}-\mathrm{CD}_{2} \mathrm{Cl}_{2}\right), 67.57 \mathrm{ppm}\left(d_{8}\right.$-THF) or $49.15 \mathrm{ppm}\left(d_{4}-\mathrm{CD}_{3} \mathrm{OD}\right)$ for ${ }^{13} \mathrm{C}$ spectra. Coupling constants, $J$ (in $\mathrm{Hz}$ ), were obtained by the first-order analysis. Infrared spectra were recorded on a Thermo Nicolet 7600 FTIR spectrometer equipped with a Spectra Tech InspectIR Plus microscopic accessory using KBr-diluted samples and a diffuse reflectance technique (DRIFT) (128 or more scans at resolution $4 \mathrm{~cm}^{-1}$ ). Raman spectra of solid samples were recorded on a DXR Raman microscope (Thermo Scientific) using excitations across the whole visible region $\left(\lambda_{\text {ex }}=445,532,633\right.$ and $780 \mathrm{~nm}$ ) and usual laser power at the sample from 0.1 to $0.4 \mathrm{~mW}$. UV/VIS spectra were recorded on a Shimadzu UV-2401PC instrument and photoluminescence spectra on a Fluorolog 3-22 Jobin Yvon Spex instrument, using a four-window quartz cuvette (1 cm) for solutions and highly oriented pyrolytic graphite (NT-MDT Co., Russia) as substrate for films. The emission spectra were recorded with excitation wavelength, $\lambda_{\mathrm{ex}}$, matching the absorption maximum of the measured compound. Quantum yields, $\phi_{\mathrm{F}}$, of photoluminescence were determined by means of a comparison of the integrated spectrum of the compound in 
question with that of the standard: quinine sulfate diluted solution in $0.5 \mathrm{M} \mathrm{H}_{2} \mathrm{SO}_{4}\left(\phi_{\mathrm{F}}=0.54 ; \lambda_{\mathrm{ex}}=380 \mathrm{~nm}\right)$. Absolute quantum yields for solid samples were measured using integration sphere Quanta- $\varphi$ F-3029. Fluorescence decay was monitored using a FluoroHub single photon counting controller on a Fluorolog 3-22 Jobin Yvon Spex instrument with excitation at $\lambda_{\mathrm{ex}}=378 \mathrm{~nm}$ for solutions and $\lambda_{\mathrm{ex}}=472 \mathrm{~nm}$ for films. Viscometric measurements were done on a Lovis $2000 \mathrm{M} / \mathrm{Me}$ microviscometer (Anton Paar). SEC analyses were done on a Spectra Physics Analytical HPLC instrument fitted with two SEC columns Polymer Labs (Bristol, UK) Mixed-D, Mixed-E and THERMO UV6000 DAD detector. $\mathrm{CHCl}_{3}+\mathrm{CH}_{3} \mathrm{CN}$ (1/1 by vol) (CHROMASOLV, Riedel-deHaen) containing $\mathrm{Bu}_{4} \mathrm{~N}^{+} \mathrm{PF}_{6}{ }^{-}\left(0.05 \mathrm{~mol} \mathrm{dm}^{-3}\right)$ was used as an eluent $\left(0.7 \mathrm{~mL} \mathrm{~min}^{-1}\right)$.

\section{Complexation experiments}

In a typical complexation experiment a measured volume of a solution of $\mathrm{Zn}^{2+}$ or $\mathrm{Fe}^{2+}$ perchlorate $\left(2 \times 10^{-3} \mathrm{M}\right)$ in $\mathrm{CHCl}_{3}+$ $\mathrm{CH}_{3} \mathrm{CN}(1 / 1$ by vol) or $\mathrm{MeOH}$ was added into a solution of particular unimer in $\left(2 \times 10^{-5} \mathrm{M}\right)$ in the same solvent. The metal to unimer $\left(\mathrm{Mt}^{2+} / \mathrm{U}\right)$ composition ratio varied from 0 to 3 . The UV/vis absorption and the photoluminescence emission spectra were measured for each solution at room temperature one day after preparing.

\section{Syntheses of bisterpyridines}

2,5-(3-(6-bromohexyl)thiophene-2,5-diyl)bis(4,4,5,5-tetramethyl1,3,2-dioxaborolane). To a solution of 3-(6-bromohexyl)thiophene $(2.1 \mathrm{~g} ; 8.45 \mathrm{mmol})$ in dry hexane $(20 \mathrm{~mL})$ $[\mathrm{Ir}(\mathrm{OMe})(\mathrm{COD})]_{2}(42 \mathrm{mg}, 0.06 \mathrm{mmol})$ and dtbpy $(150 \mathrm{mg}$, $0.56 \mathrm{mmol}$ ) were added. The solution was bubbled with argon and HBpin (4 mL, $3.53 \mathrm{~g}, 27.6 \mathrm{mmol}$ ) was added. The reaction mixture was heated at $50{ }^{\circ} \mathrm{C}$ for 4 days. Then the mixture was diluted with water $(20 \mathrm{~mL})$. After an hour of stirring in an open vessel the solution was extracted with $\mathrm{CH}_{2} \mathrm{Cl}_{2}(3 \times 50 \mathrm{~mL})$. The organic layer were combined, dried with $\mathrm{MgSO}_{4}$, filtered off and evaporated to get the product as a brownish oil. The product was used in following reaction as obtained without further purification. (2.3 g, $4.6 \mathrm{mmol}, 55 \%$ ).

${ }^{1} \mathrm{H}$ NMR (400 MHz, $\left.\mathrm{CDCl}_{3}, \delta / \mathrm{ppm}\right): 7.50\left(\mathrm{~s}, 1 \mathrm{H}, \mathrm{Th}^{4}\right), 3.40$ $\left(\mathrm{t}, J=6.8,2 \mathrm{H}, \mathrm{Hex}^{6}\right), 2.87\left(\mathrm{t}, J=7.5,2 \mathrm{H}, \mathrm{Hex}^{1}\right), 1.87-1.83(\mathrm{~m}, 2 \mathrm{H}$, $\left.\mathrm{Hex}^{5}\right), 1.64-1.57$ (m, 2H, Hex $\left.{ }^{2}\right), 1.49-1.41\left(\mathrm{~m}, 4 \mathrm{H}, \mathrm{Hex}^{3}+\mathrm{Hex}^{4}\right)$, 1.37-1.32 (m, 32H, $\left.\mathrm{CH}_{3}{ }^{-}\right) .{ }^{13} \mathrm{C}$ NMR (101 $\left.\mathrm{MHz}, \mathrm{CDCl}_{3}, \delta / \mathrm{ppm}\right)$ : 154.61, 139.46, 84.0, 83.56, 34.0, 32.69, 31.42, 29.67, 28.28, 27.92, 24.75. ${ }^{11} \mathrm{~B}$ NMR (128.3 $\left.\mathrm{MHz}, \mathrm{CDCl}_{3}, \delta / \mathrm{ppm}\right): 22.24$. FT-IR (cm ${ }^{-1}$ ) 3427 (w), 2983 (s), 2940 (s), 2861 (s), 1537 (s), 1483 (s), 1469 (s), 1453 (m), 1396 (s), 1346 (m), 1297 (w), 1275 (w), 1214 (w), 1168 (s), 1152 (s), 1111 (w), 1048 (m), 963 (m), $925(\mathrm{w}), 860(\mathrm{~s}), 828(\mathrm{~m}), 786(\mathrm{w}), 728(\mathrm{~m}), 688(\mathrm{~m}), 671(\mathrm{~s})$, $647(\mathrm{~s}), 577(\mathrm{~m}), 562(\mathrm{~m}), 520(\mathrm{~m}), 427(\mathrm{~m})$. HRMS found $m / z$ : $521.1673[\mathrm{M}+\mathrm{Na}]^{+}, \mathrm{C}_{22} \mathrm{H}_{37} \mathrm{O}_{4} \mathrm{~B}_{2} \mathrm{BrNaS}$ requires: 521. 1674.

2,5-Bis(2,2' $: 6^{\prime}, 2^{\prime \prime}$-terpyridine-4' -yl)-3-(6-bromohexyl)thiophene, M-Br. 2,5-(3-(6-Bromohexyl)thiophene-2,5-diyl)bis(4,4,5,5-tetramethyl1,3,2-dioxaborolane) (1.13 g, $2.26 \mathrm{mmol}$ ), Brtpy (1.47 g, $4.7 \mathrm{mmol}$ ), $\mathrm{K}_{2} \mathrm{CO}_{3}(1.9 \mathrm{~g}, 13.8 \mathrm{mmol})$ and Peppsi-IPr (100 mg, $\left.0.15 \mathrm{mmol}\right)$ were placed in the Schlenk tube and vacuum was applied.
The tube was filled with argon and toluene $(16 \mathrm{~mL})$ and methanol $(16 \mathrm{~mL})$ were added. The reaction mixture was heated at $88{ }^{\circ} \mathrm{C}$ overnight. After cooling to room temperature the mixture was diluted with $\mathrm{CH}_{2} \mathrm{Cl}_{2}(50 \mathrm{~mL})$ and washed with water $(3 \times 150 \mathrm{~mL})$. The organic phase was dried with $\mathrm{MgSO}_{4}$, filtered off and evaporated. Crude product was dissolved in the smallest amount of THF and hexane was added. After precipitation of white solid the mixture was filtered and the powder was collected. The residual solution was evaporated, dissolved in THF and precipitated again. White powder (0.46 g, $0.65 \mathrm{mmol}, 29 \%)$.

${ }^{1} \mathrm{H}$ NMR (400 MHz, $\left.\mathrm{CDCl}_{3}, \delta / \mathrm{ppm}\right)$ : 8.79-8.68 (m, $12 \mathrm{H}$, $\left.\mathrm{A}^{6}+\mathrm{A}^{3}+\mathrm{B}^{3}\right), 7.94-7.89\left(\mathrm{~m}, 4 \mathrm{H}, \mathrm{A}^{4}\right), 7.79\left(\mathrm{~s}, 1 \mathrm{H}, \mathrm{C}^{4}\right), 7.42-7.37$ $\left(\mathrm{m}, 4 \mathrm{H}, \mathrm{A}^{5}\right), 3.38\left(\mathrm{t}, J=6.9,2 \mathrm{H}, \mathrm{Hex}^{6}\right), 2.95-2.91\left(\mathrm{~m}, 2 \mathrm{H}, \mathrm{Hex}^{1}\right)$, 1.89-1.79 (m, 4H, Hex $\left.{ }^{2}+\mathrm{Hex}^{5}\right), 1.49-1.46\left(\mathrm{~m}, 2 \mathrm{H}, \mathrm{Hex}^{3}+\mathrm{Hex}^{4}\right)$. ${ }^{13} \mathrm{C}$ NMR (101 MHz, $\left.\mathrm{CDCl}_{3}, \delta / \mathrm{ppm}\right): 155.76,149.14,143.85$, 143.12, 142.19, 141.02, 137.0, 128.98, 123.96, 121.33, 120.55, 117.05, 33.9, 32.70, 30.65, 29.22, 28.52, 27.92. FT-IR $\left(\mathrm{cm}^{-1}\right)$ : 3056 (m), 3011 (m), 2932 (s), 2858 (m), 1597 (s), 1581 (s), 1565 (s), 1467 (s), 1441 (m), 1404 (s), 1310 (m), 1267 (m), 1124 (w), 1095 (w), 1073 (w), 1029 (w), $989(\mathrm{~m}), 888(\mathrm{~m}), 846(\mathrm{w}), 792(\mathrm{~s})$, $744(\mathrm{~s}), 677(\mathrm{~m}), 659(\mathrm{~m}), 621(\mathrm{~m}), 560(\mathrm{w}), 513(\mathrm{~m})$. HRMS found $m / z: 709.1746[\mathrm{M}+\mathrm{H}]^{+}, \mathrm{C}_{40} \mathrm{H}_{34} \mathrm{~N}_{6}$ BrS requires: 709.1746.

3,3'-Bis(6-bromohexyl)-2,2'-bithiophene. 2-Bromo-3-(6-bromohexyl)thiophene $(1 \mathrm{~mL}, 1.25 \mathrm{~g}, 3.84 \mathrm{mmol}), \mathrm{B}_{2} \mathrm{pin}_{2}(0.48 \mathrm{~g}$, $1.9 \mathrm{mmol}$ ), $\mathrm{K}_{2} \mathrm{CO}_{3}(1.57 \mathrm{~g}, 11.4 \mathrm{mmol}$ ) and Peppsi-IPr (50 mg, $0.07 \mathrm{mmol}$ ) were placed into the Schlenk tube and vacuum was applied. After filling the tube with argon, toluene $(15 \mathrm{~mL})$ and methanol $(15 \mathrm{~mL})$ were added and the reaction mixture was heated at $90{ }^{\circ} \mathrm{C}$ for 18 hours. The mixture was cooled down and diluted with $\mathrm{CH}_{2} \mathrm{Cl}_{2}(50 \mathrm{~mL})$. The solution was washed with water $(3 \times 150 \mathrm{~mL})$, dried with $\mathrm{MgSO}_{4}$, filtered off and evaporated. The crude product was purified on column chromatography (silica, $\mathrm{CH}_{2} \mathrm{Cl}_{2}+$ hexane 1/1). Yellowish oil $(0.34 \mathrm{~g}$, $0.69 \mathrm{mmol}, 36 \%)$.

${ }^{1} \mathrm{H}$ NMR (400 MHz, $\left.\mathrm{CDCl}_{3}, \delta / \mathrm{ppm}\right): 7.37\left(\mathrm{~d}, J=5.5,2 \mathrm{H}, \mathrm{Th}^{4}\right)$, $6.99\left(\mathrm{~d}, J=5.5,2 \mathrm{H}, \mathrm{Th}^{5}\right), 3.38\left(\mathrm{t}, J=6.8,4 \mathrm{H}, \mathrm{Hex}^{6}\right), 2.52(\mathrm{t}, J=7.8$, $\left.4 \mathrm{H}, \operatorname{Hex}^{1}\right), 1.82-1.75\left(\mathrm{~m}, 4 \mathrm{H}, \operatorname{Hex}^{5}\right), 1.61-1.53\left(\mathrm{~m}, 4 \mathrm{H}, \mathrm{Hex}^{2}\right)$, 1.41-1.34 (m, 8H, Hex $\left.{ }^{3}+\mathrm{Hex}^{4}\right) .{ }^{13} \mathrm{C} \mathrm{NMR} \mathrm{(101} \mathrm{MHz,} \mathrm{CDCl}_{3}$, $\delta / \mathrm{ppm}): 143.04,129.72,129.45,126.56,34.38,33.91,32.71$, 31.60, 28.99, 27.93. FT-IR ( $\left.\mathrm{cm}^{-1}\right)$ : 3101 (w), $3059(\mathrm{w}), 3002(\mathrm{w})$, 2932 (s), 2854 (s), 1519 (w), 1460 (m), 1437 (m), 1409 (w), 1371 (w), 1294 (w), 1257 (m), 1232 (m), 1090 (w), 1049 (w), 879 (w), 831 (m), $803(\mathrm{w}), 774(\mathrm{w}), 723(\mathrm{~m}), 693(\mathrm{~m}), 645(\mathrm{~m}), 561(\mathrm{~m})$. HRMS found $m / z: 491.0072[\mathrm{M}+\mathrm{H}]^{+}, \mathrm{C}_{20} \mathrm{H}_{29} \mathrm{Br}_{2} \mathrm{~S}_{2}$ requires: 491.0072 .

$5,5^{\prime}$-(3,3'-Bis(6-bromohexyl)-2,2' -bithiophene-5, $5^{\prime}$-diyl)bis(4,4,5,5-tetramethyl-1,3,2-dioxaborolane). 3,3'-Bis(6-bromohexyl)2,2'-bithiophene (0.34 g, $0.69 \mathrm{mmol})$, dtbpy (23 $\mathrm{mg}, 0.08 \mathrm{mmol}$ ) and $[\operatorname{Ir}(\mathrm{OMe})(\mathrm{COD})]_{2}(30 \mathrm{mg}, 0.04 \mathrm{mmol})$ were placed in the flask. The flask was flushed with argon and THF $(7 \mathrm{~mL})$ and hexane $(7 \mathrm{~mL})$ were added. HBpin $(0.4 \mathrm{~mL}, 0.35 \mathrm{~g}, 2.76 \mathrm{mmol})$ was added through a septum and the reaction mixture was heated at $55{ }^{\circ} \mathrm{C}$ for 48 hours. The reaction mixture was diluted with water $(20 \mathrm{~mL})$ and stirred in an open vessel for an hour. Then the solution was extracted with $\mathrm{CH}_{2} \mathrm{Cl}_{2}(50 \mathrm{~mL})$. The organic layer was dried with $\mathrm{MgSO}_{4}$, filtered off and evaporated to get the product as a brownish oil. (0.48 g, $0.64 \mathrm{mmol}, 93 \%$ ). 
${ }^{1} \mathrm{H}$ NMR (400 MHz, $\left.\mathrm{CD}_{2} \mathrm{Cl}_{2}, \delta / \mathrm{ppm}\right): 7.46\left(\mathrm{~s}, 2 \mathrm{H}, \mathrm{Th}^{4}\right), 3.37$ $\left(\mathrm{t}, J=7.0,4 \mathrm{H}, \mathrm{Hex}^{6}\right), 2.51\left(\mathrm{~m}, 4 \mathrm{H}, \mathrm{Hex}^{1}\right), 1.83-1.80(\mathrm{~m}, 4 \mathrm{H}$, $\left.\operatorname{Hex}^{5}\right), 1.57-1.53\left(\mathrm{~m}, 12 \mathrm{H}, \operatorname{Hex}^{2}-\mathrm{Hex}^{4}\right), 1.33\left(\mathrm{~s}, 32 \mathrm{H}, \mathrm{CH}_{3}-\right)$. ${ }^{13} \mathrm{C}$ NMR (101 MHz, $\left.\mathrm{CD}_{2} \mathrm{Cl}_{2}, \delta / \mathrm{ppm}\right): 144.06,139.25,84.73$, $34.67,33.30,30.98,28.96,28.44,26.14,25.14 .{ }^{11} \mathrm{~B}$ NMR (128 MHz, $\left.\mathrm{CD}_{2} \mathrm{Cl}_{2}, \delta / \mathrm{ppm}\right):$ 24.39. FT-IR $\left(\mathrm{cm}^{-1}\right): 3394(\mathrm{~m})$, 2976 (s), 2931 (s), 2856 (m), 1618 (w), 1530 (m), 1474 (s), 1379 (s), $1330(\mathrm{~s}), 1298(\mathrm{~m}), 1267(\mathrm{~m}), 1214(\mathrm{w}), 1165(\mathrm{~m}), 1142$ (s), $1027(\mathrm{~m}), 982(\mathrm{~m}), 961(\mathrm{w}), 925(\mathrm{w}), 852(\mathrm{~s}), 802(\mathrm{~m}), 727(\mathrm{w}), 665$ (m), $577(\mathrm{w}), 519(\mathrm{w})$. HRMS found $m / z: 765.1595[\mathrm{M}+\mathrm{Na}]^{+}$, $\mathrm{C}_{32} \mathrm{H}_{50} \mathrm{O}_{4} \mathrm{~B}_{2} \mathrm{Br}_{2} \mathrm{NaS}_{2}$ requires: 765.1596.

5,5'-Bis(2,2' :6' $2^{\prime \prime}$-terpyridine-4'-yl)-3,3' -di(6-bromohexyl)-2,2' bithiophene, B-Br. 5,5'-(3,3'-Bis(6-bromohexyl)-2,2'-bithiophene5,5'-diyl)bis(4,4,5,5-tetramethyl-1,3,2-dioxaborolane) $(0.48 \mathrm{~g}$, $0.64 \mathrm{mmol})$, Brtpy (0.43 g, $1.37 \mathrm{mmol}), \mathrm{K}_{2} \mathrm{CO}_{3}(0.52 \mathrm{~g}, 3.76 \mathrm{mmol})$ and Peppsi-IPr (26 mg, $0.04 \mathrm{mmol})$ were placed in the Schlenk flask and vacuum was applied. The flask was flushed with argon and toluene $(15 \mathrm{~mL})$ and methanol $(15 \mathrm{~mL})$ were added. The reaction mixture was heated at $90{ }^{\circ} \mathrm{C}$ for 18 hours. After cooling to room temperature the reaction mixture was diluted with $\mathrm{CH}_{2} \mathrm{Cl}_{2}$ $(50 \mathrm{~mL})$ and washed with water $(3 \times 100 \mathrm{~mL})$, then dried with $\mathrm{MgSO}_{4}$, filtered off and evaporated. The crude product was purified on column chromatography (aluminium oxide, hexane + THF 3/2). Yellow solid (0.12 g, $0.13 \mathrm{mmol}, 20 \%)$.

${ }^{1} \mathrm{H}$ NMR (400 MHz, THF, $\left.\delta / \mathrm{ppm}\right): 8.83\left(\mathrm{~s}, 4 \mathrm{H}, \mathrm{B}^{3}\right.$ ), 8.72-8.70 $\left(\mathrm{m}, 8 \mathrm{H}, \mathrm{A}^{3}+\mathrm{A}^{6}\right), 7.94-7.89\left(\mathrm{~m}, 4 \mathrm{H}, \mathrm{A}^{4}\right), 7.87\left(\mathrm{~s}, 2 \mathrm{H}, \mathrm{C}^{4}\right), 7.41-$ $7.37\left(\mathrm{~m}, 4 \mathrm{H}, \mathrm{A}^{5}\right), 3.42\left(\mathrm{t}, J=6.8,4 \mathrm{H}, \mathrm{Hex}^{6}\right), 2.77-2.74(\mathrm{~m}, 4 \mathrm{H}$, $\left.\operatorname{Hex}^{1}\right), 1.89-1.79\left(\mathrm{~m}, 8 \mathrm{H}, \mathrm{Hex}^{2}+\mathrm{Hex}^{5}\right), 1.51-1.38\left(\mathrm{~m}, 8 \mathrm{H}, \mathrm{Hex}^{3}+\right.$ $\left.\mathrm{Hex}^{4}\right) .{ }^{13} \mathrm{C} \mathrm{NMR}\left(101 \mathrm{MHz}, \mathrm{CDCl}_{3}, \delta / \mathrm{ppm}\right):$ 156.08, 155.99, 149.12, 143.68, 143.09, 141.51, 136.84, 130.30, 127.45, 123.90, 121.32, 116.81, 33.88, 32.68, 30.49, 29.01, 28.51, 27.95. FT-IR $\left(\mathrm{cm}^{-1}\right): 3057(\mathrm{w}), 3010(\mathrm{w}), 2930(\mathrm{~m}), 2854(\mathrm{~m}), 1597(\mathrm{~m}), 1581$ (s), 1565 (s), 1528 (w), 1466 (m), 1443 (m), 1419 (w), 1403 (m), 1382 (w), 1360 (w), 1263 (m), 1209 (w), 1147 (w), 1123 (w), 1094 (m), 1072 (m), $1018(\mathrm{~m}), 989(\mathrm{~m}), 959(\mathrm{w}), 901(\mathrm{w}), 881(\mathrm{~m}), 847$ (m), $791(\mathrm{~s}), 773(\mathrm{~m}), 746(\mathrm{~m}), 734(\mathrm{~m}), 688(\mathrm{w}), 677(\mathrm{w}), 658(\mathrm{~m})$, $648(\mathrm{w}), 633(\mathrm{w}), 621(\mathrm{~m}), 507(\mathrm{w})$. HRMS found $\mathrm{m} / \mathrm{z}: 953.1673$ $[\mathrm{M}+\mathrm{H}]^{+}, \mathrm{C}_{50} \mathrm{H}_{47} \mathrm{~N}_{6} \mathrm{Br}_{2} \mathrm{~S}_{2}$ requires: 953.1665.

\section{Quarternization}

A weighed amount of a given Br-unimer was dissolved in THF (conc. $4 \times 10^{-3} \mathrm{M}$ ), trimethylamine was added (10 eq.) as ethanol solution $(4.2 \mathrm{M})$ and the mixture was kept at $25{ }^{\circ} \mathrm{C}$ for four days. The precipitated product was isolated by centrifugation, washed with THF and dried under vacuum.

6-[2,5-Bis(2,2' :6' ,2 ${ }^{\prime \prime}$-terpyridine-4'-yl)thiophene-3-yl]hexan-1-yl trimethylammonium bromide, $\mathbf{M}-\mathbf{N}^{+}$. Yellowish powder $37 \%$. ${ }^{1} \mathrm{H}$ NMR (400 MHz, $\left.\mathrm{CD}_{3} \mathrm{OD}, \delta / \mathrm{ppm}\right): 8.70-8.69\left(\mathrm{~m}, 4 \mathrm{H}, \mathrm{A}^{6}\right)$, 8.64-8.60 (m, $6 \mathrm{H}, \mathrm{A}^{3}+\mathrm{B}^{3}$ or $\left.\mathrm{B}^{3 \prime}\right), 8.54\left(\mathrm{~s}, 2 \mathrm{H}, \mathrm{B}^{3 \prime}\right.$ or $\left.\mathrm{B}^{3}\right), 8.01-7.96$ $\left(\mathrm{m}, 4 \mathrm{H}, \mathrm{A}^{4}\right), 7.80\left(\mathrm{~s}, 1 \mathrm{H}, \mathrm{C}^{4}\right), 7.49-7.45\left(\mathrm{~m}, 4 \mathrm{H}, \mathrm{A}^{5}\right), 3.25-3.20(\mathrm{~m}, 2 \mathrm{H}$, $\left.\mathrm{Hex}^{6}\right) 3.03\left(\mathrm{~s}, 9 \mathrm{H}, \mathrm{N}-\left(\mathrm{CH}_{3}\right)_{3}\right), 2.98\left(\mathrm{t}, J=7.6,2 \mathrm{H}, \mathrm{Hex}^{1}\right), 1.87-1.72(\mathrm{~m}$, $\left.4 \mathrm{H}, \mathrm{Hex}^{5}+\mathrm{Hex}^{2}\right), 1.54-1.50\left(\mathrm{~m}, 2 \mathrm{H}, \mathrm{Hex}^{4}\right), 1.42-1.38\left(\mathrm{~m}, 2 \mathrm{H}, \mathrm{Hex}^{3}\right)$. ${ }^{13} \mathrm{C}$ NMR (101 MHz, CD $\left.{ }_{3} \mathrm{OD}, \delta / \mathrm{ppm}\right): 157.74,157.61,157.20,150.66$, 145.41, 144.51, 139.06, 130.85, 126.0, 123.15, 121.48, 117.93, 68.14, 53.78, 31.73, 30.13, 27.47, 27.45, 24.20. FT-IR ( $\left.\mathrm{cm}^{-1}\right): 3412(\mathrm{~m})$, 3055 (m), 3012 (m), 2940 (s), 2861 (m), 1767 (w), 1722 (m), 1597 (s),
1582 (s), 1557 (s), 1468 (s), 1441 (m), 1403 (s), 1381 (m), 1266 (m), 1168 (w), 1126 (w), 1095 (w), 1073 (m), 1031 (m), 989 (m), 966 (w), $888(\mathrm{~m}), 846$ (w), $793(\mathrm{~s}), 745(\mathrm{~s}), 677(\mathrm{~m}), 660(\mathrm{~m}), 621(\mathrm{~m}), 589(\mathrm{w})$, $569(\mathrm{w}), 513(\mathrm{~m}), 502(\mathrm{w}), 471(\mathrm{w})$. HRMS found $\mathrm{m} / \mathrm{z}: 688.3218$ $[\mathrm{M}+\mathrm{H}]^{+}, \mathrm{C}_{43} \mathrm{H}_{42} \mathrm{~N}_{7} \mathrm{~S}$ requires: 688.3217 .

$6,6^{\prime}$-[5,5'-Bis $\left(2,2^{\prime}: 6^{\prime}, 2^{\prime \prime}\right.$-terpyridine-4' - yl $)-2,2^{\prime}$-bithiophene-3, $3^{\prime}$ diyl]bis[hexan-1,1'-diyl trimethylammonium]bromide, B- $\mathbf{N}^{+}$. Orange powder $41 \% .{ }^{1} \mathrm{H}$ NMR (400 $\left.\mathrm{MHz}, \mathrm{CD}_{3} \mathrm{OD}, \delta / \mathrm{ppm}\right)$ : 8.72-8.71 (m, $\left.4 \mathrm{H}, \mathrm{A}^{6}\right), 8.62-8.59\left(\mathrm{~m}, 4 \mathrm{H}, \mathrm{A}^{3}\right), 8.56\left(\mathrm{~s}, 4 \mathrm{H}, \mathrm{B}^{3}\right)$, $8.01\left(\mathrm{td}, J=7.7, J=1.6,4 \mathrm{H}, \mathrm{A}^{4}\right), 7.8\left(\mathrm{~s}, 2 \mathrm{H}, \mathrm{C}^{4}\right), 7.53-7.50(\mathrm{ddd}$, $\left.J=7.4, J=4.8, J=1.3,4 \mathrm{H}, \mathrm{A}^{5}\right), 3.31-3.28\left(\mathrm{~m}, 4 \mathrm{H}, \mathrm{Hex}^{6}\right), 3.07$ $\left(\mathrm{s}, 18 \mathrm{H}, \mathrm{N}-\left(\mathrm{CH}_{3}\right)_{3}\right), 2.74\left(\mathrm{t}, J=7.7,4 \mathrm{H}, \mathrm{Hex}^{1}\right), 1.83-1.75(\mathrm{~m}, 8 \mathrm{H}$, $\left.\mathrm{Hex}^{5}+\mathrm{Hex}^{2}\right)$, 1.53-1.30 (m, 8H, $\left.\mathrm{Hex}^{3}+\mathrm{Hex}^{4}\right){ }^{13} \mathrm{C} \mathrm{NMR}$ (101 MHz, $\left.\mathrm{CD}_{3} \mathrm{OD} \delta / \mathrm{ppm}\right): 157.82,157.67,157.22,150.47$, $144.68,139.25,139.14,132.09,129.53,126.11,123.30,117.82$, 68.19, 53.76, 31.78, 30.24, 27.49, 26.07, 24.25. FT-IR $\left(\mathrm{cm}^{-1}\right)$ : 3404 (s), 3058 (m), 3015 (m), 2933 (s), 2858 (m), 1722 (s), 1674 (s), 1584 (s), 1567 (s), 1469 (s), 1402 (s), 1265 (m), 1210 (m), 1176 (w), $1124(\mathrm{w}), 1094(\mathrm{w}), 1072$ (m), 1044 (w), 1018 (m), 991 (m), $971(\mathrm{w}), 907(\mathrm{~m}), 886(\mathrm{~m}), 846(\mathrm{~m}), 792(\mathrm{~s}), 743(\mathrm{~s}), 659(\mathrm{~s}), 622$ (s), $586(\mathrm{w}), 573(\mathrm{w}), 529(\mathrm{~m}), 507(\mathrm{w}), 490(\mathrm{w}), 457(\mathrm{w}), 430(\mathrm{w})$. HRMS found $m / z$ : $456.2343[\mathrm{M}+\mathrm{H}]^{2+}, \mathrm{C}_{56} \mathrm{H}_{64} \mathrm{~N}_{8} \mathrm{~S}_{2}$ requires: 456.2342 .

\section{Conclusions}

The here exploited route to alcohol-soluble ionic unimers includes preparation of their $\omega$-bromoalkyl precursors, which is not too easy but already well mastered procedure, and replacing terminal bromine atoms with ammonium type groups. An inverse approach, coupling of ionic thiophenes with Brtpy, is difficult owing to diverse solubility of reactants, the catalyst and the auxiliary base. Though the modification of bromo-unimers to the ionic ones seems trivial, it is inhibited by tpy end-groups and, therefore, is well feasible only with highly reactive amines.

A spectroscopic study of unimers' assembly with metal ions in dilute solutions provided the UV/vis and luminescence spectral patterns characteristic of the $\mathrm{U}-\mathrm{Mt}^{2+}-\mathrm{U}$ type dimers, dynamer chains with free tpy end-groups and dynamer chains capped with metal ions. Absorption spectra of SEC fractions of non-ionic Fe-dynamer $\mathbf{P}_{\mathbf{F e}} \mathbf{M}$-Br well agree with the dilute solution spectra of the systems with corresponding composition ratios $r$. The SEC study further proved that the constitutional dynamics of Zn-dynamers is fast while that of Fe-dynamers is slow. It also provided a good calibration dependence, which allowed determining the average values of the degree of polymerization of the dynamer in solutions; this characteristic of dynamers is otherwise almost not accessible and is the subject of the question after almost every conference presentation. Unfortunately, the ionic Fe-dynamers were not effectively separated in SEC columns due to the strong interference of the adsorption mode.

Relative stability of Fe-dynamer chains in solutions (changes lasting for two months are reported in the literature $)^{48}$ should be attributed to the MLCT within the tpy- $\mathrm{Fe}^{2+}-t p y$ linkages. The here presented UV/vis spectra as well as the spectra presented 
earlier $^{47,50,52}$ confirm that the MLCT bands are contributed also with transitions within central blocks of unimeric units. The resonance Raman spectra obtained in this study indicate that the transitions within the central block significantly affect the longer-wavelength part of the MLCT band while its shorterwavelength arm is mainly contributed with transitions within tpy end-groups.

\section{Acknowledgements}

Financial support of the Czech Science Foundation (P108/12/1143) and the Grant Agency of Charles University (project 64213) is greatly acknowledged.

\section{References}

1 J. Lehn, Prog. Polym. Sci., 2005, 30, 814.

2 J. W. Steed and J. L. Atwood, Supramolecular chemistry, John Wiley \& Sons, Ltd, 2nd edn, 2009.

3 A. Ciferri, in Supramolecular Polymers, ed. A. Ciferri, CRC Press, 2nd edn, 2005.

4 M. Beley, D. Delabouglise, G. Houppy, J. Husson and J.-P. Petit, Inorg. Chim. Acta, 2005, 358, 3075.

5 A. Wild, F. Schlütter, G. M. Pavlov, C. Friebe, G. Festag, A. Winter, M. D. Hager, V. Cimrová and U. S. Schubert, Macromol. Rapid Commun., 2010, 31, 868.

6 A. El-Ghayoury, A. P. H. J. Schenning and E. W. Meijer, J. Polym. Sci., Part A: Polym. Chem., 2002, 40, 4020.

7 A. Harriman, G. Izzet, S. Goeb, A. De Nicola and R. Ziessel, Inorg. Chem., 2006, 45, 9729.

8 S. C. Yu, C. C. Kwok, W. K. Chan and C. M. Che, Adv. Mater., 2003, 15, 1643.

9 P. R. Andres and U. S. Schubert, Adv. Mater., 2004, 16, 1043.

10 A. Barbieri, B. Ventura, F. Barigelletti, A. De Nicola, M. Quesada and R. Ziessel, Inorg. Chem., 2004, 43, 7359.

11 Q. Wu, J. Wang, H. Hu, Y. Shangguan, F. Fu, M. Yang, F. Dong and G. Xue, Inorg. Chem. Commun., 2011, 14, 484.

12 R. Siebert, A. Winter, M. Schmitt, J. Popp, U. S. Schubert and B. Dietzek, Macromol. Rapid Commun., 2012, 33, 481.

13 R. Dobrawa, M. Lysetska, P. Ballester, M. Grüne and F. Würthner, Macromolecules, 2005, 38, 1315.

14 F. S. Han, M. Higuchi, Y. Akasaka, Y. Otsuka and D. G. Kurth, Thin Solid Films, 2008, 516, 2469.

15 P. D. Vellis, J. A. Mikroyannidis, C. Lo and C. Hsu, J. Polym. Sci., Part A: Polym. Chem., 2008, 46, 7702.

16 Y. Chen and H. Lin, J. Polym. Sci., Part A: Polym. Chem., 2007, 45, 3243.

17 A. Winter, C. Friebe, M. Chiper, M. D. Hager and U. S. Schubert, J. Polym. Sci., Part A: Polym. Chem., 2009, 3, 4083.

18 F. Barigelletti and L. Flamigni, Chem. Soc. Rev., 2000, 29, 1.

19 M. Chiper, R. Hoogenboom and U. S. Schubert, Macromol. Rapid Commun., 2009, 30, 565.

20 A. Maier, K. Cheng, J. Savych and B. Tieke, ACS Appl. Mater. Interfaces, 2011, 3, 2710.
21 A. Wild, A. Teichler, C.-L. Ho, X.-Z. Wang, H. Zhan, F. Schlütter, A. Winter, M. D. Hager, W.-Y. Wong and U. S. Schubert, J. Mater. Chem. C, 2013, 1, 1812.

22 Y. Li, T. Ren and W.-J. Dong, J. Photochem. Photobiol., A, 2013, 251, 1.

23 R. Siebert, Y. Tian, R. Camacho, A. Winter, A. Wild, A. Krieg, U. S. Schubert, J. Popp, I. G. Scheblykin and B. Dietzek, J. Mater. Chem., 2012, 22, 16041.

24 P. Bláhová, J. Zedník, I. Šloufová, J. Vohlídal and J. Svoboda, Soft Mater., 2014, 12, 214.

25 L. Fillaud, G. Trippé-Allard and J. C. Lacroix, Org. Lett., 2013, 15, 1028.

26 M. Barón, K.-H. Hellwich, M. Hess, K. Horie, A. D. Jenkins, R. G. Jones, J. Kahovec, P. Kratochvíl, W. V. Metanomski, W. Mormann, R. F. T. Stepto, J. Vohlídal and E. S. Wilks, Pure Appl. Chem., 2009, 81, 1131.

27 M. Hess, R. G. Jones, J. Kahovec, T. Kitayama, P. Kratochvil, P. Kubisa, W. Mormann, R. F. T. Stepto, D. Tabak, J. Vohlidal and E. S. Wilks, Pure Appl. Chem., 2006, 78, 2067.

28 J. Svoboda, P. Stenclova, F. Uhlík, J. Zedník and J. Vohlídal, Tetrahedron, 2011, 67, 75.

29 G. a Chotana, V. a Kallepalli, R. E. Maleczka and M. R. Smith, Tetrahedron, 2008, 64, 6103.

30 T. Ishiyama, Y. Nobuta, J. F. Hartwig and N. Miyaura, Chem. Commun., 2003, 2924.

31 H. A. Ho and M. Leclerc, J. Am. Chem. Soc., 2003, 125, 4412. 32 F. Le Floch, H.-A. H. a. Ho, P. Harding-Lepage, M. Bédard, R. Neagu-Plesu and M. Leclerc, Adv. Mater., 2005, 17, 1251.

33 D. Bondarev, J. Zedník, I. Šloufová, A. Sharf, M. Procházka, J. Pfleger and J. Vohlídal, J. Polym. Sci., Part A: Polym. Chem., 2010, 48, 3073.

34 U. S. Schubert, H. Hofmeier and G. R. Newkome, Modern Terpyridine Chemistry, Wiley-VCH Verlag GmbH, Weinheim, 2006.

35 J. N. Demas and B. A. DeGraft, in Topics in Fluorescence Spectroscopy: Volume 4: Probe Design and Chemical Sensing, ed. J. R. Lakowicz, Springer Science \& Business Media, 1994, ch. 4.5 , p. 81.

36 R. Englman and J. Jortner, Mol. Phys., 1970, 18, 145.

37 R. Siebert, A. Winter, M. Schmitt, J. Popp, U. S. Schubert and B. Dietzek, Macromol. Rapid Commun., 2012, 33, 481.

38 I. Šloufová, B. Vlčková, M. Procházka, J. Svoboda and J. Vohlídal, J. Raman Spectrosc., 2014, 45, 338.

39 R. Horvath, J. Lombard, J.-C. Leprêtre, M.-N. Collomb, A. Deronzier, J. Chauvin and K. C. Gordon, Dalton Trans., 2013, 42, 16527.

40 S. Kazim, J. Pfleger, K. Halašová, M. Procházka, D. Bondarev and J. Vohlídal, Eur. Phys. J.: Appl. Phys., 2011, 55, 23905.

41 S. Kazim, J. Pfleger, M. Procházka, D. Bondarev and J. Vohlídal, J. Colloid Interface Sci., 2011, 354, 611.

42 E. A. Bazzaoui, M. Bazzaoui, J. Aubard, J. S. Lomas, N. Félidj and G. Lévi, Synth. Met., 2001, 123, 299.

43 K. Mukherjee, D. Bhattacharjee and T. Misra, J. Colloid Interface Sci., 1999, 213, 46.

44 I. Srnova-Šloufová, B. Vlčková, T. L. Snoeck, D. J. Stufkens and P. Matjka, Inorg. Chem., 2000, 39, 3551. 
45 P. K. Mallick, G. D. Danzer, D. P. Strommen and R. Kincaid James, J. Phys. Chem., 1988, 92, 5628.

46 D. P. Strommen, P. K. Mallick, G. D. Danzer, R. S. Lumpkin and R. Kincaid James, J. Phys. Chem., 1990, 94, 1358.

47 T. Vitvarová, J. Zedník, M. Bláha, J. Vohlídal and J. Svoboda, Eur. J. Inorg. Chem., 2012, 3866.

48 G. Schwarz, I. Haßlauer and D. G. Kurth, Adv. Colloid Interface Sci., 2014, 207, 107.
49 V. Stepanenko, M. Stocker, P. Müller, M. Büchner and F. Würthner, J. Mater. Chem., 2009, 19, 6816.

50 R. A. Dobrawa, PhD thesis, Bayerischer Julius-MaximiliansUniversität Würzburg, 2004.

51 G. Schwarz, Y. Bodenthin, T. Geue, J. Koetz and D. G. Kurth, Macromolecules, 2010, 43, 494.

52 R. Dobrawa and F. Würthner, J. Polym. Sci., Part A: Polym. Chem., 2005, 43, 4981. 